\title{
An Assessment of the Potential for Co-located Offshore Wind and Wave Farms in Ireland
}

\author{
Eilis Gaughan ${ }^{\mathrm{a}}$, Breiffni Fitzgerald ${ }^{\mathrm{b}, *}$ \\ ${ }^{a}$ Electricity Supply Board (ESB), Dublin, Ireland \\ ${ }^{b}$ School of Engineering, Trinity College Dublin, Ireland
}

\begin{abstract}
Ireland's geographic location along the Atlantic Ocean means that it has one of the highest resources of wind and wave energy on the planet. Despite this, successful integration of wave energy into the Irish energy system has not been achieved. Ireland has a unique opportunity to not only develop wave energy but to also consider the benefits associated with co-located wind-wave farms. Co-located energy farms can offer a more predictable, less variable renewable energy source. This study investigates the synergies between offshore wind and wave resources at four locations off the Irish coast. Raw wind and wave data consisting of hourly observations from the Irish Marine Institute are used to characterise the available wind and wave resources over a ten-year period (2009-2019). The data is analysed in terms of power potential, temporal and spatial variability and correlation. An inter-annual and seasonal analysis of the cross-correlation between wind and wave resources is carried out. The results demonstrate that while favourable low correlation values and long-time lags exist off the Northwest coast, there is high inter-annual variability. The East coast displays low variability of correlations and lags inter-annually with little complementary behaviour between the two resources or scope for co-location.
\end{abstract}

Keywords: Wind, Wave, Offshore, Co-location, Ireland

\section{Introduction}

Renewable energy plays a vital global role in the reduction of greenhouse gas (GHG) emissions and the mitigation of climate change. In the past decade the European Union (EU) has endorsed an integrated approach to climate and energy policy that aims to combat climate change and increase the EU's energy security. The EU's 20-20-20 targets specify a reduction in EU GHG emissions of at least $20 \%$ below 1990 levels by 2020. Additionally, $20 \%$ of EU energy consumption must come from Renewable Energy Source (RES) by 2020. Despite these targets, Ireland, an EU member state, will fail to meet its legally binding RES commitment. Ireland is one of only four EU states that is expected to miss their 2020 goals. At least $16 \%$ of Ireland's gross final energy consumption in 2020 must be supplied by RES, rising to $32 \%$ by 2030 . Latest Irish figures show that only $11 \%$ gross final energy consumption from RES is being achieved at present [1]. Closing the gap on these energy targets will be a significant challenge for Ireland to achieve given projections of energy demand increases of between $11 \%$ and $30 \%$ over the next ten years [2].

\footnotetext{
${ }^{*}$ Corresponding author

Email address: breiffni.fitzgerald@tcd.ie (Breiffni Fitzgerald)
} 


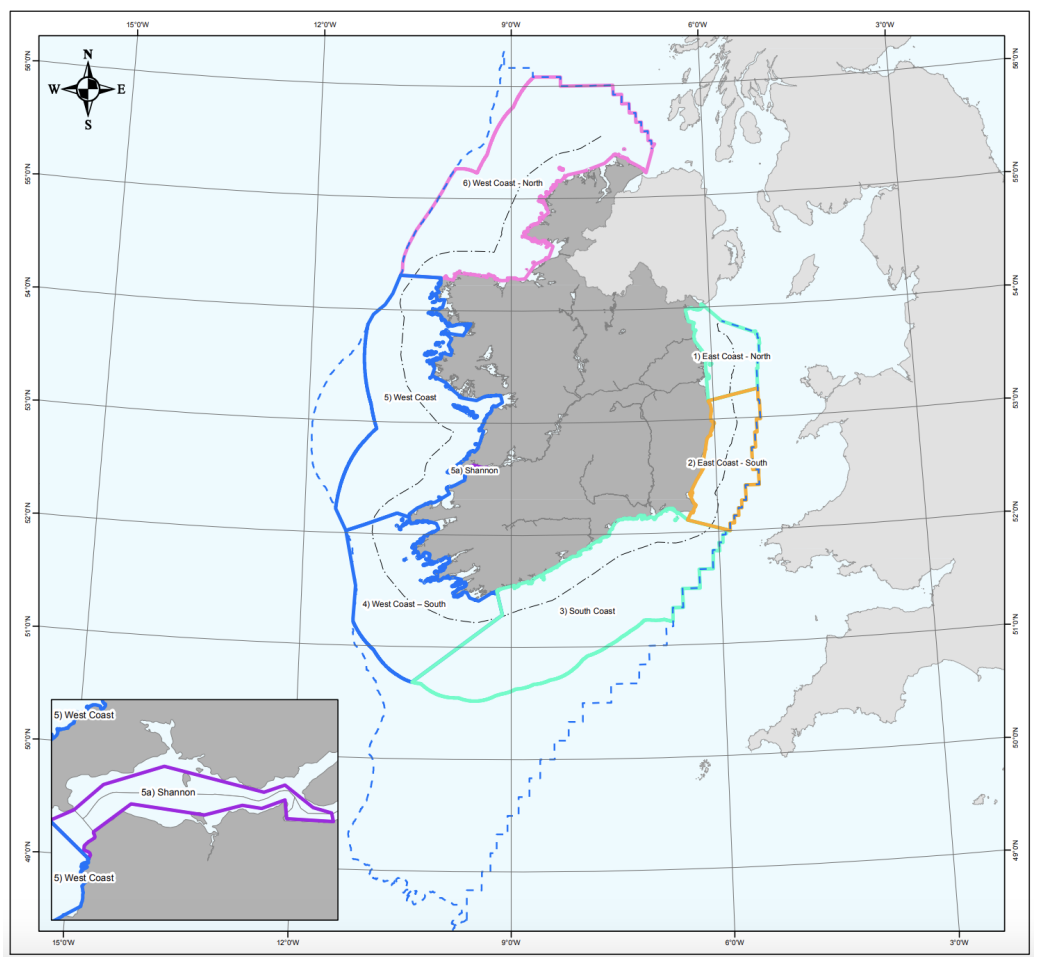

Figure 1: Ireland - offshore energy assessment areas [3]

Table 1: Irish coast wind and wave resource (in MW) [3]

\begin{tabular}{|l|c|c|c|c|}
\hline Assessment area & $\begin{array}{l}\text { Fixed wind } \\
\text { (MW) }\end{array}$ & $\begin{array}{l}\text { Wave (MW) } \\
\text { 10 - 100m depth }\end{array}$ & $\begin{array}{l}\text { Wave (MW) } \\
\text { 100 - 200m depth }\end{array}$ & $\begin{array}{l}\text { Floating wind } \\
\text { (MW) }\end{array}$ \\
\hline 1 - East Coast - North & $1200-1500$ & 0 & 0 & 0 \\
2 - East Coast - South & $3000-3300$ & 0 & 0 & 0 \\
3 - South Coast & $1500-1800$ & 0 & 0 & 6000 \\
4 - West Coast - South & $600-900$ & $500-600$ & $3000-3500$ & $5000-6000$ \\
5 - West Coast & 500 & 5000 & $6000-7000$ & 7000 \\
- West Coast - North & $3000-4500$ & $7000-8000$ & $6000-7000$ & $7000-8000$ \\
\hline
\end{tabular}

Ireland's location on the western edge of Europe along the Atlantic Ocean endows it with significant wind and wave resources. Ocean energy has been encouraged at a national policy level with the Offshore Renewable Energy Development Plan published in 2014 [3]. Assessment areas are indicated in the map provided in Figure 1 and the total amount of development (in MW) that could potentially occur off the coast of Ireland without likely significant adverse effects on the environment is outlined in Table 1.

Wind energy is a significant contributor to the energy mix in Ireland. The past decade has seen Irish onshore wind grow impressively from $1112 \mathrm{GWh}$ of electricity produced in 2005 to $8640 \mathrm{GWh}$ in 2018 [1]. In 2018, wind generation accounted for $28 \%$ of the electricity generated and was Ireland's second largest source of electricity. Ireland's installed wind capacity is now close to $3.7 \mathrm{GW}$ and all but $25 \mathrm{MW}$ of this is onshore wind, the next decade will see a large increase in offshore wind development [3].

Wave energy could contribute to Ireland's future energy mix. Recently two ocean energy test sites have been developed on the Irish West coast; the quarter scale test site in Galway bay and the full-scale Atlantic 
Marine Energy Test Site (AMETS) in Belmullet, County Mayo (both in Assessment area 5). Globally the annual average power resource of deep-water waves varies from $30-70 \mathrm{~kW} / \mathrm{m}$ wave crest with a peak of $100 \mathrm{~kW} / \mathrm{m}$ in the Northeast Atlantic Ocean [4]. Wave power around the Irish coast has been found at the high end of this varying in the range of $53-76 \mathrm{~kW} / \mathrm{m}$ with particularly significant resources available close to the AMETS location off the West coast [5, 4].

Despite the vast resource available from offshore wind and wave energy the successful integration of these technologies at scale into the Irish energy system has not yet been achieved. In addition to the challenges associated with costs and O\&M, there are significant issues associated with hours of zero power generation and intermittency on the electrical grid from variable energy sources. High levels of variable power penetration can be problematic and require additional system balancing to ensure security of supply [6]. Several authors have explored the viability of combining offshore wind turbines and WECs into a single energy farm to address the key challenges associated with standalone renewables [7, 8]. Co-locating wind-wave technologies where a low correlation exists can provide a more balanced and predictable system.

\subsection{Aims of this study}

A limited number of studies have undertaken a combined resource analysis for wind and wave energy in Ireland. Most existing studies have used data from hindcast projects performed by operational centres such as the European Centre for Medium-Range Weather Forecasts (ECMWF) [9]. While the use of these datasets provides longer temporal data and wider spatial data there are limitations regarding coarse spatial resolution. One study in the literature uses raw data, however, the time period considered is quite small at three years [10].

The present study considers ten years of raw wind and wave data at four locations off the Irish coast. This study characterises the potential for offshore wind and wave energy by considering the theoretical power output of both resources, undertaking a detailed variability analysis and assessing the combined resource through correlation. In this study:

- A comprehensive dataset of the potential wind and wave power resource across four offshore locations in Ireland is developed. The study considers a time period of ten years from January 2009 to January 2019 .

- An estimate of the wave power potential at each offshore location is calculated by considering irregular wave theory applied to ten years of raw data. Previous studies have used regular wave theory [10] or modelled data [9].

- An analysis is undertaken which assesses the temporal and spatial variability of the wind and wave resources while considering the complementarity between both resources at single site locations. The cross correlation between wind and wave energy sources and the time lag that exists at each location is calculated from the raw data. The correlation results are verified by a theoretical analysis.

- An inter-annual and seasonal cross correlation analysis is carried out for each offshore site over the ten year period. It is shown that while favourable low correlation values and long-time lags exist off the Northwest coast of Ireland, there is high inter-annual variability which has not been reported before. This conclusion is only possible by considering a long study period of ten years.

The present study thus assesses the potential of the wind and wave resource off the Irish coast in the context of co-location of wind and wave farms.

\section{Methodology}

\subsection{Available data and offshore locations}

The dataset used was generated from the Irish Marine Weather Buoy Network (IMWBN). This is a network of five weather buoys at different locations off the coast Ireland. The weather buoys are situated in marine waters with M2 in the Irish Sea (East coast), M3 off the Southeast, M4 off the Northwest and M5 
off the Southwest coasts, Table 2 provides the exact locations of the buoys. M1 was not considered in this analysis as the M1 station data collection was discontinued in 2007. The locations of the buoys are shown on the map provided from Met Éireann, the Irish National Meteorological Service, in Figure 2.

Table 2: IMWBN - Buoy Locations

\begin{tabular}{|l|l|}
\hline Buoy & Coordinates \\
\hline $\mathrm{M} 1$ & $53.1266^{\circ} \mathrm{N} 11.2000^{\circ} \mathrm{W}$ \\
\hline $\mathrm{M} 2$ & $53.4800^{\circ} \mathrm{N} 05.4250^{\circ} \mathrm{W}$ \\
\hline $\mathrm{M} 3$ & $51.2166^{\circ} \mathrm{N} 10.5500^{\circ} \mathrm{W}$ \\
\hline $\mathrm{M} 4$ & $55.0000^{\circ} \mathrm{N} 10.0000^{\circ} \mathrm{W}$ \\
\hline $\mathrm{M} 5$ & $51.6900^{\circ} \mathrm{N} 06.7040^{\circ} \mathrm{W}$ \\
\hline $\mathrm{M} 6$ & $53.0605^{\circ} \mathrm{N} 15.9300^{\circ} \mathrm{W}$ \\
\hline
\end{tabular}

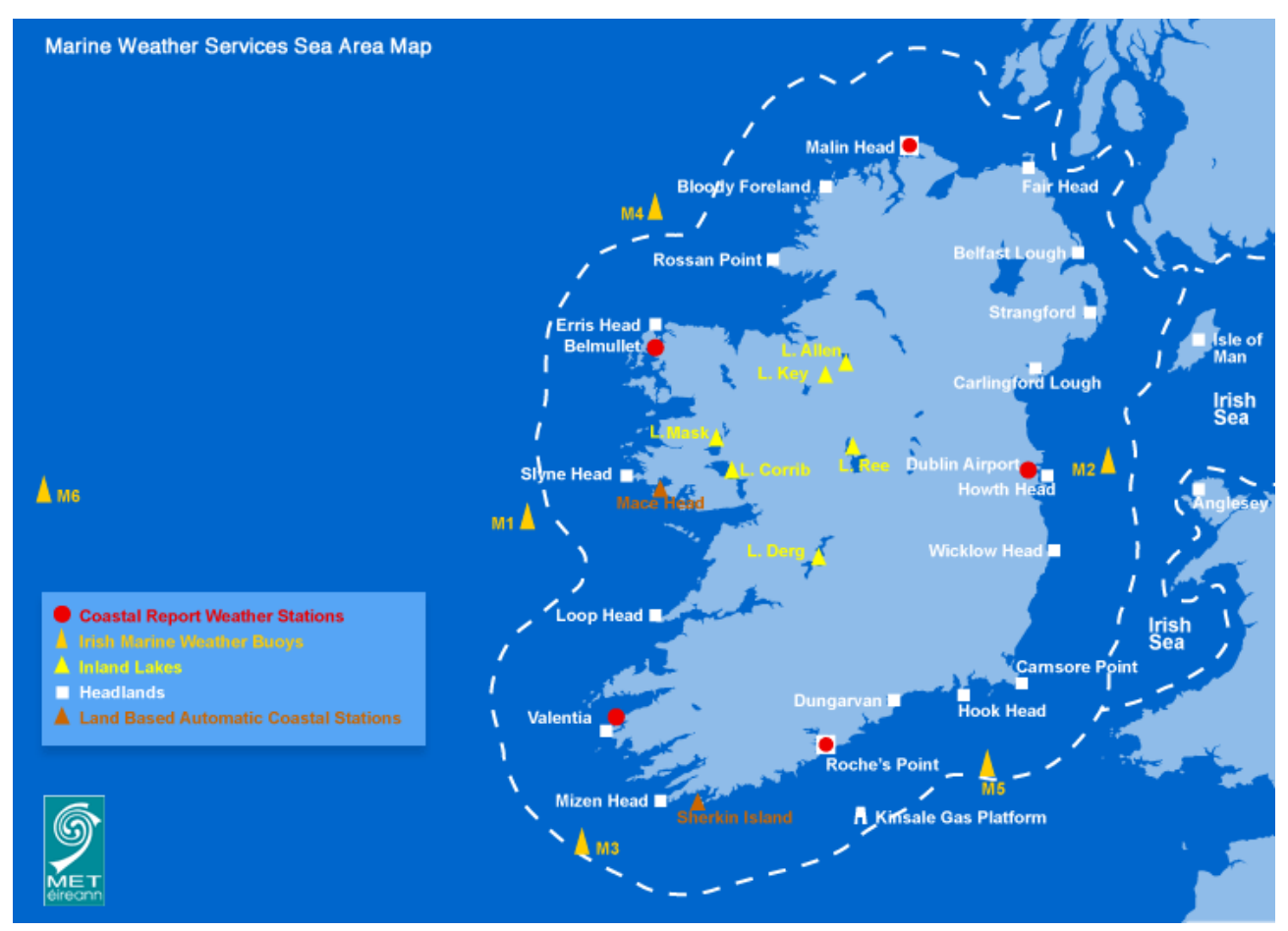

Figure 2: IMWBN location map (after Met Éireann)

The parameters considered were hourly spaced observations of wind speed $\left(v_{w}\right)$, significant wave height $\left(H_{s}\right)$ and mean wave period $\left(T_{z}\right)$ which were measured via the Fugro Oceanor wavesense buoy. These weather buoys are moored surface buoys with instruments that collect weather and ocean data including air temperature, atmospheric humidity, sea surface temperature, sea temperature and salinity on moored chain, wave statistics and wind speed/direction. Wind speed is recorded using a Young Ultrasonic Anemometer which is a 2-axis, no moving parts sensor. Wind speed is measured in knots and recorded every 10 minutes and reported hourly. The buoy is equipped with two wind sensors which are located at the sensor carrier arm at the mast top 1 and mast top 2. Significant wave height is calculated as four times the root mean square (RMS) value of the wave, this is averaged over 17.5 minutes. The mean wave period is a record of 17.5 minutes of the number of times a wave passes through mean water level in an upward direction. 
The instrument used for wave height and period is the OCEANOR Wavesense wave sensor and data-logger which is designed for operation in remote areas. The sensors working principle is the common inertial sensor working principle. Accelerometers, rate gyros and magnetometers are mounted orthogonally to provide the basic data. These data are then used as input to calculate Heave, Roll, Pitch, Surge, Sway and Compass time series. Significant wave height, wave direction, wave period and several other statistical parameters are then obtained from these time series. The data was extracted for the ten-year period from 2009 to 2019.

The data contained several missing data points. For the quantitative estimates of wind and wave power (monthly and seasonal variability) the World Meteorological Organization (WMO) guidelines for data completeness were followed [11]. The WMO recommends that, for the calculation of monthly mean values where a monthly value is the mean of that month's daily values, it should not be calculated if either of the following criteria are satisfied:

1. Observations are missing for 11 or more days of the month;

2. Observations are missing for a period of 5 or more consecutive days during the month.

Additionally, days which had greater than two hours of missing measurements were omitted from the analysis. See Appendix A for the details of data considered in this study.

\subsection{Wind and wave power potential}

Wind speed $\left(v_{w}\right)$ data was provided at approximately 3 metres above sea level at each offshore location. The vertical profile of the wind speed was modelled to a height of 124 meters by using the power law given in Equation 1.

$$
v_{2}=v_{1}\left(\frac{z_{2}}{z_{1}}\right)^{\alpha}
$$

where $v_{1}$ is the velocity at height $z_{1}, v_{2}$ is the velocity at height $z_{2}, z_{1}$ is the lower height (in this case $3 \mathrm{~m}), z_{2}$ is the upper height (in this case $124 \mathrm{~m}$ ) and $\alpha$ is the wind shear exponent. A value of 0.1 was taken for the wind shear exponent to reflect open water terrain [12].

Equation 2 was then used to estimate the available wind power potential of the different offshore Irish locations. For available wind power per unit of area $\left(\mathrm{m}^{2}\right)$ :

$$
P_{\text {wind }}=\frac{1}{2} \rho_{a} v_{w}^{3}
$$

where $\rho_{a}$ the density of air $\left(1.226 \mathrm{~kg} / \mathrm{m}^{3}\right)$ and $v_{w}$ is the wind speed.

Irregular wave theory was used to determine the available wave power at each of the locations. In deep water, the wave power transmitted per unit width is approximated by Equation 3 [13].

$$
P_{\text {wave }}=\frac{\rho_{w} g^{2}}{64 \pi} H_{s}^{2} T_{e}
$$

where $\rho_{w}$ is the density of water and $g$ is the acceleration due to gravity. The average value for water density was used $\left(1025 \mathrm{~kg} / \mathrm{m}^{3}\right)$ and a value of $9.81 \mathrm{~m} / \mathrm{s}^{2}$ was used for acceleration due to gravity. $H_{s}$ is the significant wave height which is directly available from the data provided by the IMWBN for each of the locations considered.

$T_{e}$ is the wave energy period. The IMWBN provides data for the peak period $T_{p}$ and the mean period (the average zero-crossing period) $T_{z}$ at each location. However, the energy period $T_{e}$ is not specified and must be estimated from one of the available variables. For the western coast of Ireland it has been shown in several studies that $T_{e}$ is approximately equal to $1.32 T_{z}[14,15,16]$. For the eastern Irish coast a value of $T_{e}=1.14 T_{z}$ is specified for the Irish Sea by the Atlas of UK Marine Renewable Energy Resources [17]. These values have been used in Equation 3 for the wave power potential calculations at western and eastern buoy locations respectively.

Equation 3 is valid for irregular waves under the deep water assumption (water depth much greater then wave length), which is true at the considered offshore locations [18]. It is acknowledged that the 
use of Equation 3 introduces some uncertainty into the resulting wave power estimates. However, since $P_{\text {wave }} \propto H_{s}^{2} T_{e}$, errors in wave period are less significant than errors in wave height (directly available from measurements). Furthermore, the use of irregular wave theory with recorded data should result in more accurate wave power estimates than reported in previous studies [9, 10].

\subsection{Spatial and temporal variability}

Seasonal variability was assessed by considering winter (December, January, and February), spring (March, April and May), summer (June, July and August) and autumn (September, October and November). Statistical indicators such as the mean and standard deviation were used in the analysis to understand how far the data fluctuated about the average.

\subsection{Correlation analysis}

Two approaches were taken to analyse the correlation between the wind and the wave resource. The first approach used observed wind speed measurements and calculated the expected wave height and wave period by using Equations 4 and 5 .

$$
\begin{gathered}
H_{s}=0.21 \frac{v_{w, 19.5}^{2}}{g} \\
T_{z}=\frac{2 \pi}{0.4} \sqrt{\frac{H_{s}}{g}}
\end{gathered}
$$

Using observed wind speed data, expected wave parameters can be calculated and compared with the observed wave parameters. It has been shown by Ochi [19] that a wind speed $v_{w, 19.5}$, measured at 19.5 $\mathrm{m}$ above the sea surface, produces, if blowing over a sufficient fetch and for enough time, a wave system defined by the following significant wave height $H_{s}$ and period $T_{z}$. Disagreement between the observed wave parameters and the calculated wave parameters suggests a low correlation between both resources and would suggest a remotely generated wave system which would likely be observed along the Atlantic coast of Ireland.

In the second approach a cross-correlation analysis was undertaken. The correlations between the two time series (wind and wave) were calculated to determine whether a time lag exists between the two resources. The cross-correlation function (CCF) was calculated using Equation 6.

$$
\frac{\Sigma_{t=1}^{n-k}\left(X_{t}-\bar{X}\right)\left(Y_{t+k}-\bar{Y}\right)}{S_{x} S_{y}}
$$

Where $n$ is the number of observations, $t$ is the row number, $k$ is the lag, $\bar{X}$ is the mean of $x$ - the first time series, $\bar{Y}$ is the mean of $y$ - the second time series, $S_{x}=\sqrt{\sum_{t=1}^{n}\left(X_{t}-\bar{X}\right)^{2}}$ and $S_{y}=\sqrt{\sum_{t=1}^{n}\left(Y_{t}-\bar{Y}\right)^{2}}$.

The cross-correlation analysis quantified the correspondence between the two variables as it considered the displacements or lag of one variable relative to the other. Only when a lag or a lead exists between the two variables can the power output variation be smoothed. For the cross correlation function the $95 \%$ confidence bounds for strict white noise were also plotted. An important consideration before running a cross correlation was to ensure both time-series were stationary. To test for stationarity, an indirect test for the existence of a unit root was applied (for details see Appendix B). The statistical test performed was the Augmented Dickey-Fuller (ADF) test. For the ADF test a p-value below 0.05 suggested the rejection of the null hypothesis at $95 \%$ confidence level and conclusion that no unit-root was present. Once the results of this statistical test suggested stationarity, the cross-correlation outputs were plotted to demonstrate the temporal lags between the wind and wave resource as well as illustrating the instantaneous correlation value which is the value which occurs at time lag zero. A correlation coefficient equal to 1 would indicate a perfect correspondence between the two power resources, whereas a correlation coefficient equal to zero would suggest no correspondence between the two resources. 


\section{Wind and wave resource assessment results}

\subsection{Wind resource}

The strongest wind resource is evident off the Northwest of Ireland at location M4. Here the average wind power (Figure 4) is $1530 \mathrm{~W} / \mathrm{m}^{2}$, a difference of approximately $360 \mathrm{~W} / \mathrm{m}^{2}$ to that of the East coast which has the lowest wind energy levels $\left(1170 \mathrm{~W} / \mathrm{m}^{2}\right)$. At M3, in the Southeast region the average wind power is $1200 \mathrm{~W} / \mathrm{m}^{2}$. The wind power across all locations is generally consistent with little spatial variation present. The seasonal average wind resource for all locations considered in this study can be seen in Figure 5 . The strongest seasonal wind resource is evident during winter at location M4 in the Northwest of Ireland. M4 also shows the largest variability with higher standard deviations to any other region. The Northwest Atlantic storm corridor may be a contributing factor in this. Across all regions seasonal and monthly wind variability is evident (Figure 3). Energy levels are three times higher in winter than summer. The most pronounced difference is evident on the Northwest coast where the difference between summer and winter is $1500 \mathrm{~W} / \mathrm{m}^{2}$.
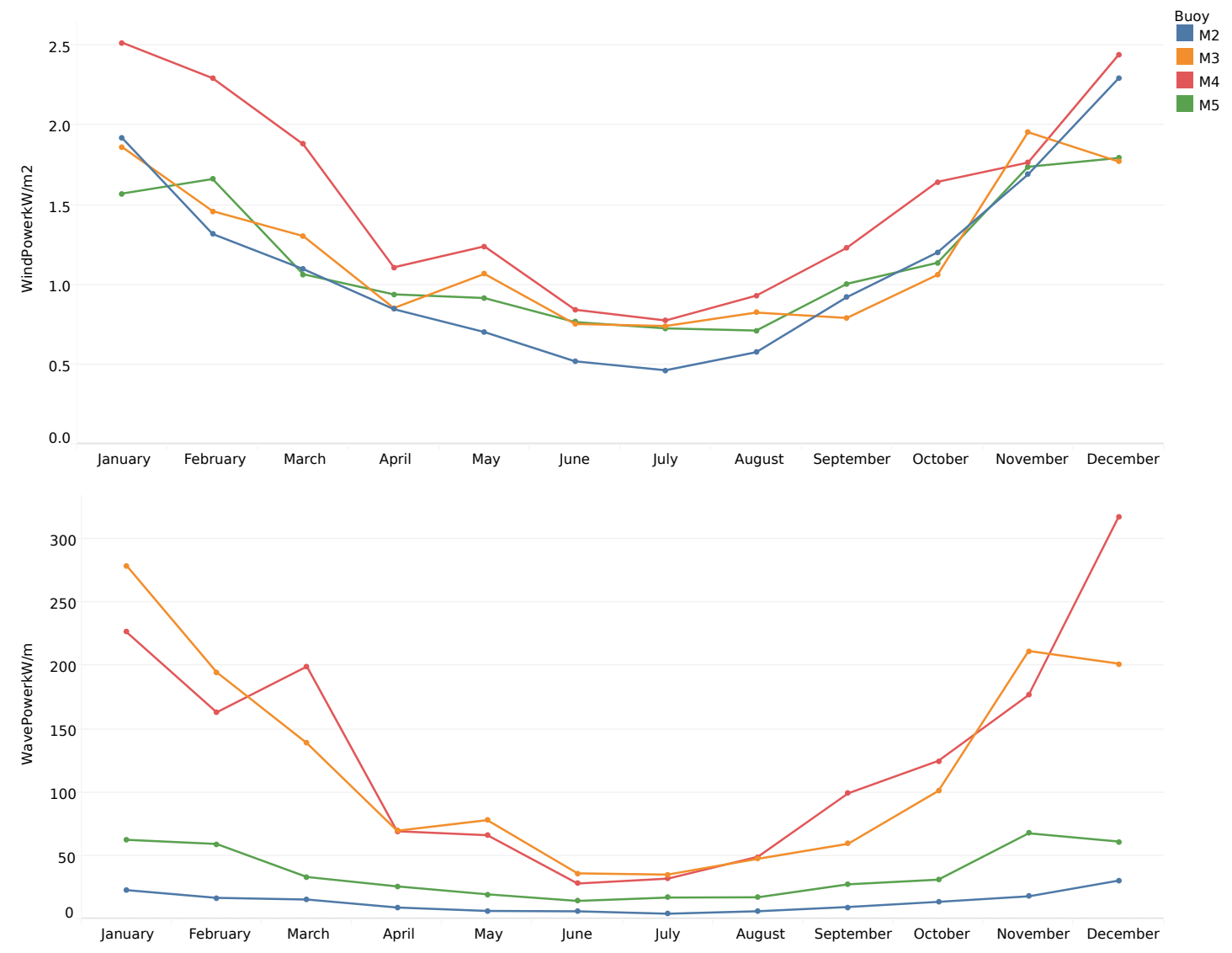

Figure 3: Wind and wave resource for study period

\subsection{Wave resource}

The highest power potential for wave energy is in the Northwest region with averages above $130 \mathrm{~kW} / \mathrm{m}$ (Figure 4), this is similar in nature to the wind observations. This is particularly dominant in the winter when the power levels are approximately $250 \mathrm{~kW} / \mathrm{m}$ (Figure 6). The mean winter values identified for 

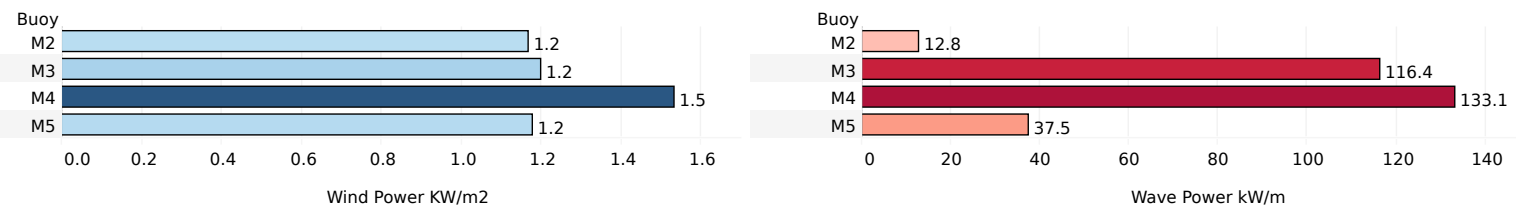

Figure 4: Average wind and wave resource for study period

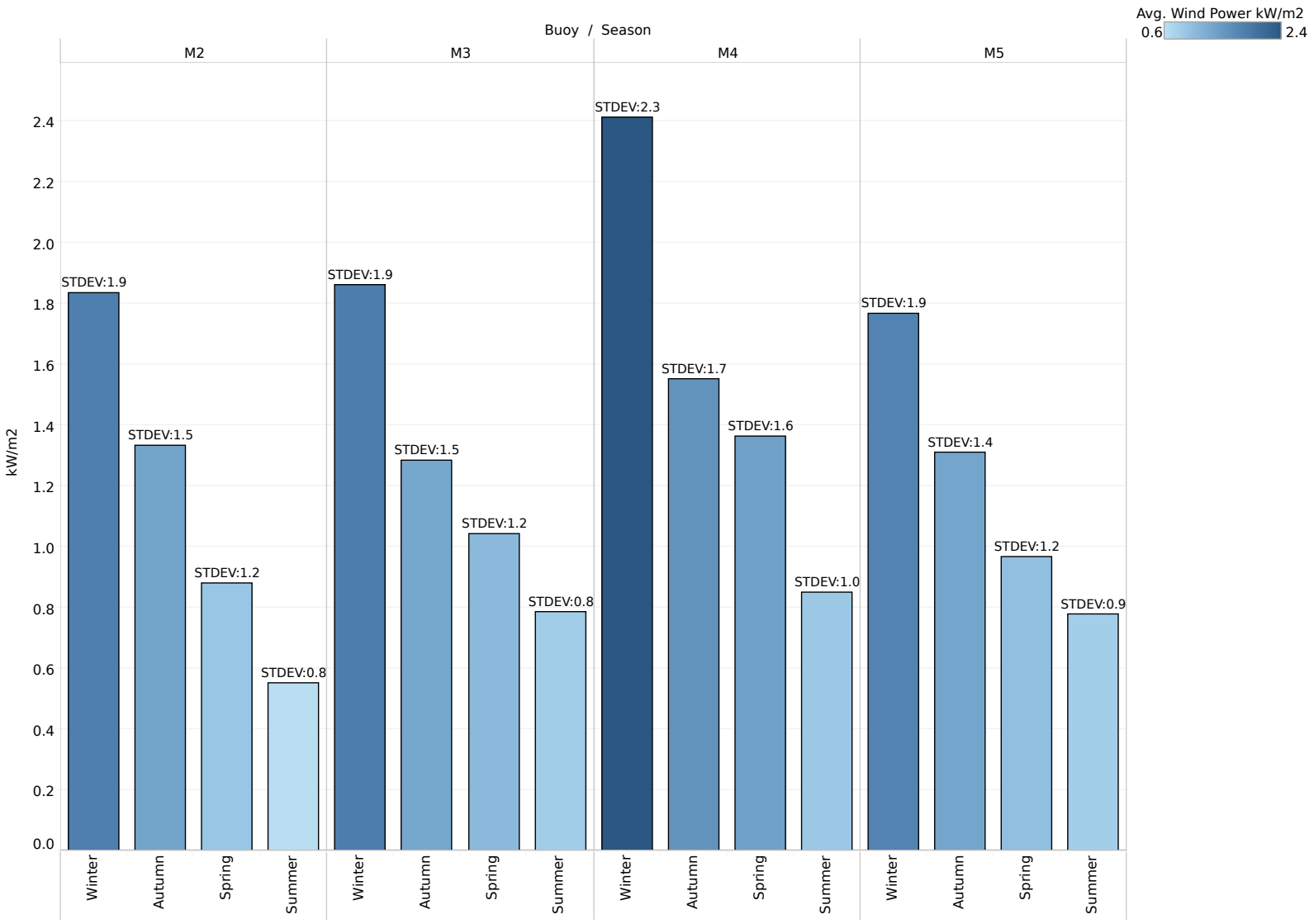

Figure 5: Seasonal averages and standard deviations for wind resource for study period

location M4 are much higher than those identified by Gallagher et al. [9] who found a wave resource of $90 \mathrm{~kW} / \mathrm{m}$ north of Malin Beg. Although location M4 presents significant potential for wave energy, the extractable energy in this area during the winter is limited due to the design limitations of WECs, resulting in a reduced exploitable energy. Summer on the Northwest coast still has significant wave power potential with average values in summer just under $40 \mathrm{~kW} / \mathrm{m}$. The energy potential for spring and autumn are similar with both seasons exposed to just under $130 \mathrm{~kW} / \mathrm{m}$. While the Southwest region experiences high-energy fluxes with averages just under $120 \mathrm{~kW} / \mathrm{m}$, a significant reduction is observed for the Southeast where averages fall below $40 \mathrm{~kW} / \mathrm{m}$. The East coast shows particularly low power potential with an average of $12 \mathrm{~kW} / \mathrm{m}$ with little seasonal and monthly variation (Figure 3). 


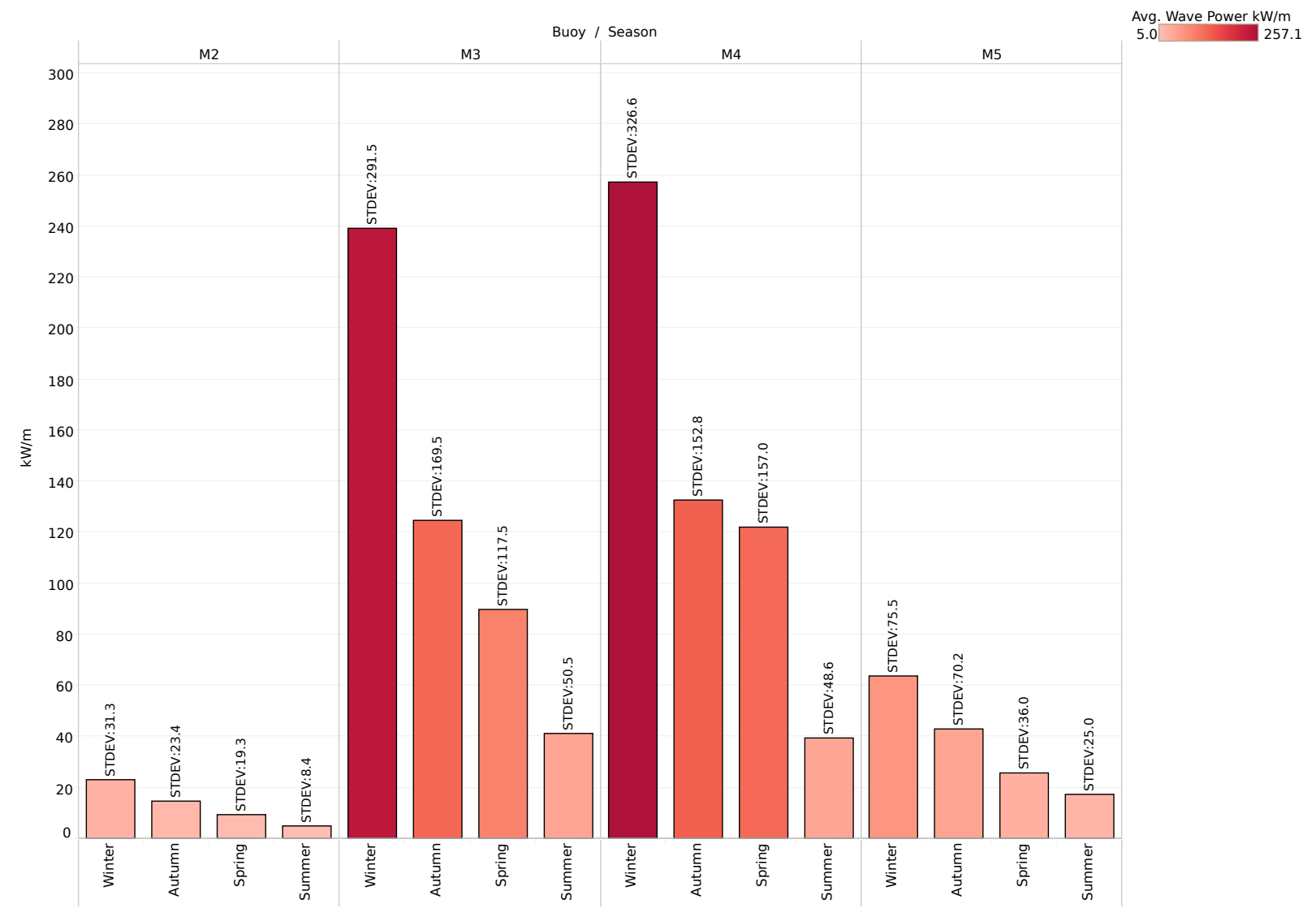

Figure 6: Seasonal averages and standard deviations for wave resource for study period

\subsection{Power smoothing and correlation analysis}

Wave formation is influenced by three distinct factors wind velocity, wind duration and fetch. Fetch represents the distance over the water that the wind can blow uninterrupted in a single direction. An increase in wind velocity, distance and duration results in larger and more energetic waves. In areas where the fetch is small, such as enclosed basins, swell formation ability is limited. This results in wave generation strongly influenced by local winds, causing a strong correlation with a minimal time lag between both resources. On the contrary, areas with a longer fetch enable the formation of large swells causing a weak correlation and larger time lag between both resources [20,21]. Locations where wind velocities are high, fetches are long, and the wave resource follows the wind resource with a significant time lag are potentially exploitable areas for co-located offshore wind and wave energy farms. In order to exploit the complementarity between both resources and tackle the challenge of intermittent supply, the inter-annual and seasonal crosscorrelation factor between both resources at single sites is analysed - this provides a useful measure of the power smoothing potential when both resources are utilized at a single site. Tables 3 - 5 provide inter-annual detail on the correlation coefficient at a time lag of zero, $c(0)$, and maximum value of correlation coefficient, $\max (C)$, with the related lag for the study period 2009 - 2019. A further detailed breakdown of annual correlations is presented in Appendix C Tables C.7- C.10.

Locations close to the long Atlantic fetch such as M3 and M4 demonstrate the lowest correlations with the longest lags. At these locations the wave resource follows the wind resource with inconsistent time delays varying from year to year. Maximum cross-correlation time lags range from 4 hours to 13 hours at M4 (Table 5). A more stable behaviour is identified for the sheltered Southeast and East locations, 
Table 3: Annual analysis of cross-correlation $(\mathrm{c}(0))$ between wind and wave resource at zero-time lag for four sites

\begin{tabular}{lllllllllll}
\hline Location & $\mathbf{2 0 0 9}$ & $\mathbf{2 0 1 0}$ & $\mathbf{2 0 1 1}$ & $\mathbf{2 0 1 2}$ & $\mathbf{2 0 1 3}$ & $\mathbf{2 0 1 4}$ & $\mathbf{2 0 1 5}$ & $\mathbf{2 0 1 6}$ & $\mathbf{2 0 1 7}$ & $\mathbf{2 0 1 8}$ \\
\hline M2 & 0.76 & 0.75 & 0.79 & 0.74 & 0.71 & 0.67 & 0.76 & 0.78 & 0.73 & 0.81 \\
M3 & 0.57 & 0.51 & 0.52 & 0.49 & 0.55 & 0.53 & 0.64 & 0.52 & 0.68 & 0.56 \\
M4 & 0.53 & 0.56 & 0.66 & 0.55 & 0.53 & 0.53 & 0.49 & 0.54 & 0.44 & 0.55 \\
M5 & 0.51 & 0.61 & 0.55 & 0.47 & 0.62 & 0.73 & 0.69 & 0.59 & 0.43 & 0.54 \\
\hline
\end{tabular}

Table 4: Annual analysis of the max cross-correlation (max (C)) between wind and wave resource for four sites

\begin{tabular}{lllllllllll}
\hline Location & $\mathbf{2 0 0 9}$ & $\mathbf{2 0 1 0}$ & $\mathbf{2 0 1 1}$ & $\mathbf{2 0 1 2}$ & $\mathbf{2 0 1 3}$ & $\mathbf{2 0 1 4}$ & $\mathbf{2 0 1 5}$ & $\mathbf{2 0 1 6}$ & $\mathbf{2 0 1 7}$ & $\mathbf{2 0 1 8}$ \\
\hline M2 & 0.81 & 0.80 & 0.84 & 0.79 & 0.77 & 0.74 & 0.82 & 0.84 & 0.78 & 0.82 \\
M3 & 0.62 & 0.60 & 0.56 & 0.56 & 0.63 & 0.58 & 0.71 & 0.57 & 0.75 & 0.69 \\
M4 & 0.61 & 0.62 & 0.72 & 0.61 & 0.62 & 0.57 & 0.62 & 0.65 & 0.53 & 0.69 \\
M5 & 0.58 & 0.69 & 0.60 & 0.53 & 0.69 & 0.79 & 0.77 & 0.63 & 0.48 & 0.64 \\
\hline
\end{tabular}

Table 5: Annual analysis of the time lags (hours) at max (C) between wind and wave resource (2009-2019) for four sites

\begin{tabular}{lllllllllll}
\hline Location & $\mathbf{2 0 0 9}$ & $\mathbf{2 0 1 0}$ & $\mathbf{2 0 1 1}$ & $\mathbf{2 0 1 2}$ & $\mathbf{2 0 1 3}$ & $\mathbf{2 0 1 4}$ & $\mathbf{2 0 1 5}$ & $\mathbf{2 0 1 6}$ & $\mathbf{2 0 1 7}$ & $\mathbf{2 0 1 8}$ \\
\hline M2 & 2 & 3 & 2 & 2 & 3 & 3 & 2 & 3 & 2 & 2 \\
M3 & 5 & 6 & 5 & 6 & 6 & 5 & 7 & 5 & 4 & 7 \\
M4 & 6 & 4 & 5 & 6 & 7 & 7 & 11 & 13 & 6 & 8 \\
M5 & 4 & 4 & 4 & 4 & 4 & 4 & 4 & 3 & 3 & 5 \\
\hline
\end{tabular}

Table 6: Correlation data at each location for the study period (2009-2019)

\begin{tabular}{|c|c|c|c|c|c|c|c|}
\hline \multirow[b]{2}{*}{ Location } & \multicolumn{3}{|c|}{$2009-2019$} & \multicolumn{4}{|c|}{ Cross-correlation at zero lag $c(0)$} \\
\hline & $c(0)$ & $\operatorname{Lag}(h)$ & $\max (C)$ & $D J F$ & $M A M$ & $J J A$ & SON \\
\hline M2 & 0.75 & 2 & 0.80 & 0.71 & 0.76 & 0.62 & 0.74 \\
\hline M3 & 0.57 & 6 & 0.63 & 0.54 & 0.49 & 0.53 & 0.55 \\
\hline M4 & 0.55 & 6 & 0.61 & 0.51 & 0.54 & 0.55 & 0.48 \\
\hline M5 & 0.54 & 4 & 0.61 & 0.52 & 0.57 & 0.63 & 0.47 \\
\hline
\end{tabular}

particularly M2 where a strong positive correlation is evident year on year with a consistent 2 to 3 hour time lag, suggesting consistent wave generation from local wind conditions.

A summary of the seasonal cross-correlations is presented in Table 6 with a further detailed breakdown available in Appendix C (Tables C.11- C.14). The seasonal mean correlation coefficient, $R^{2}$, is shown in Figure 7 for the four offshore locations considered in this study. A strong positive correlation, particularly in the spring and autumn seasons is evident between both resources at M2 on the East coast of Ireland where the $R^{2}$ value is above 0.7. The geographical location of M2 sheltered from the Atlantic Ocean and hence sheltered from Atlantic generated swells results in waves that are generated from local wind conditions rather than westerly wind systems. The Northwest and Southwest regions however show a much lower and modest positive relationship with an $R^{2}$ between 0.5 and 0.55 for all seasons. The position of these sites along the Atlantic Ocean encourages remotely generated wind systems. Figure 8 shows a linear trend line at zero-time lag for potential wind and wave power at each offshore site considered. The scatter plots in Figure 8 demonstrate the larger amount of variation evident between the two resources for the Northwest 
and Southwest locations. The East coast has a strong linear relationship with little variation.

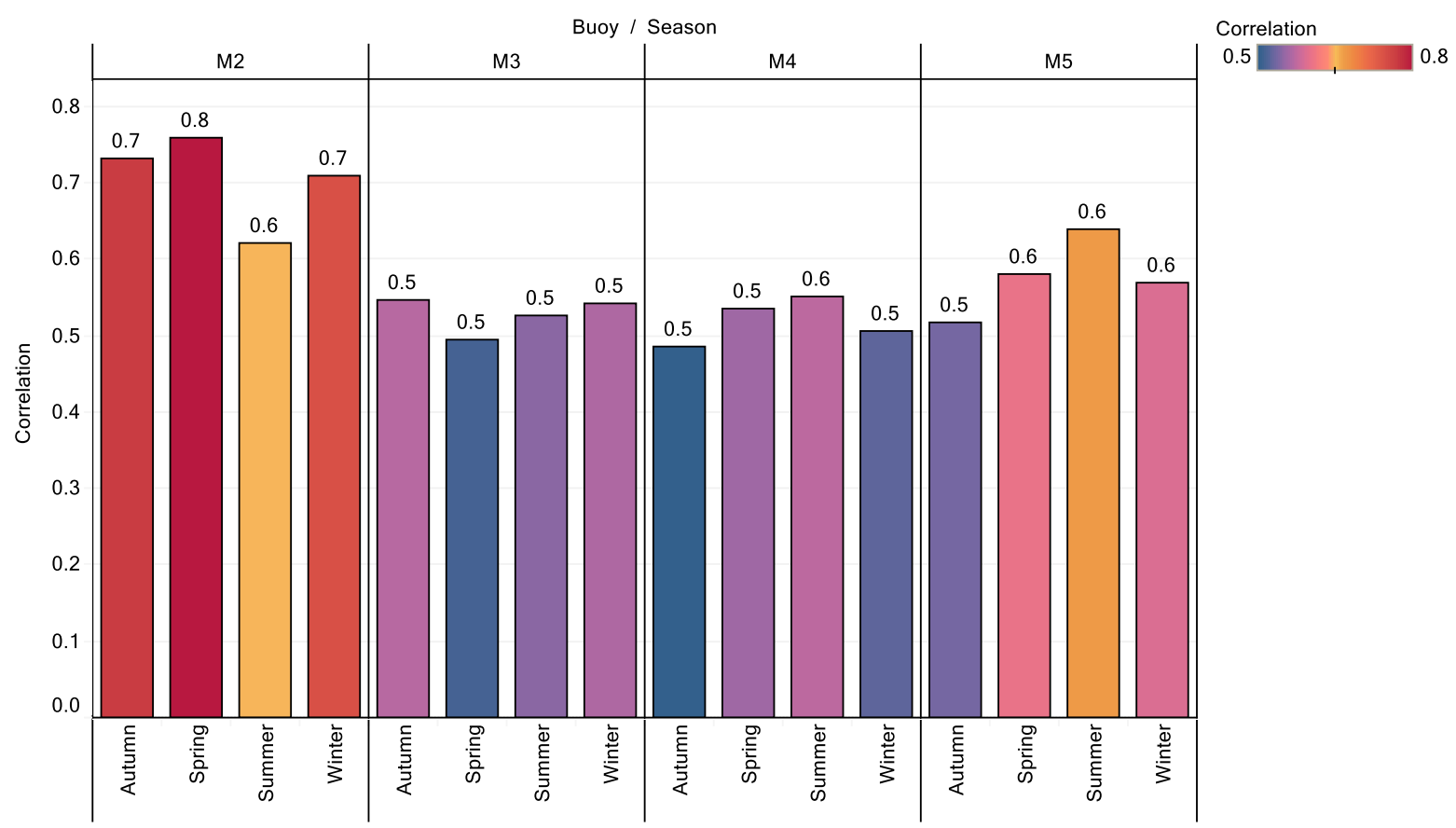

Figure 7: Seasonal mean correlations at zero time lag for potential wind and wave resource

Time series plots of wind and wave power are shown in Figure 9 for the M2 buoy (East location) and the M4 buoy (Northwest location) in winter. Figure 10 shows time series plots of wind and wave power for these two locations in summer. The time series plot for M2 shows both resources are well aligned with a minor lag of 2 hours at the maximum temporal correlation. This short lag may be the result of the time that it takes for the waves to develop from the local wind systems in the Irish sea. For the same winter period, a poor agreement is observed for the Northwest coast where the maximum point of temporal correlation is observed at a time lag of 6 hours. The extended lag may be the result of a swell superimposed on the local wind waves. Figure 11 shows the decline of the lag over time for all the offshore locations.

It is evident that the Northwest and Southwest regions see the largest time delays between wind and wave resource. The results show that in all four of the offshore locations considered in this study the wave resource lags the wind resource. This demonstrates that there exists an alternative renewable energy source available when wind falls outside the power production range. There is also the potential to smooth power output and reduce non-operational periods due to this time lag between the wind and wave resource.

\subsection{Observed and expected wave state}

To validate the assumption that the modest correlations observed at the Northwest and Southwest regions are the result of independent swells, a comparison between the observed sea state and expected sea state is made. The correlation between the observed and expected wave height and wave period, respectively can be seen in Figure 12 and Figure 13. As expected, a stronger correspondence between expected and observed wave height can be seen on the East coast, where for each season the correlation coefficient is above 0.7. The correlation is lowest for M3 in the Southwest and M4 in the Northwest region where it is expected that local wind conditions have less influence on wave generation. A low or even negative correlation is seen between observed and expected wave period for all study locations except for the East coast (Figure 13). The strong correlation between the observed and expected sea state from wind measurements on the East coast suggests the wave formation is mainly generated from local wind conditions rather than Atlantic Ocean swells. 

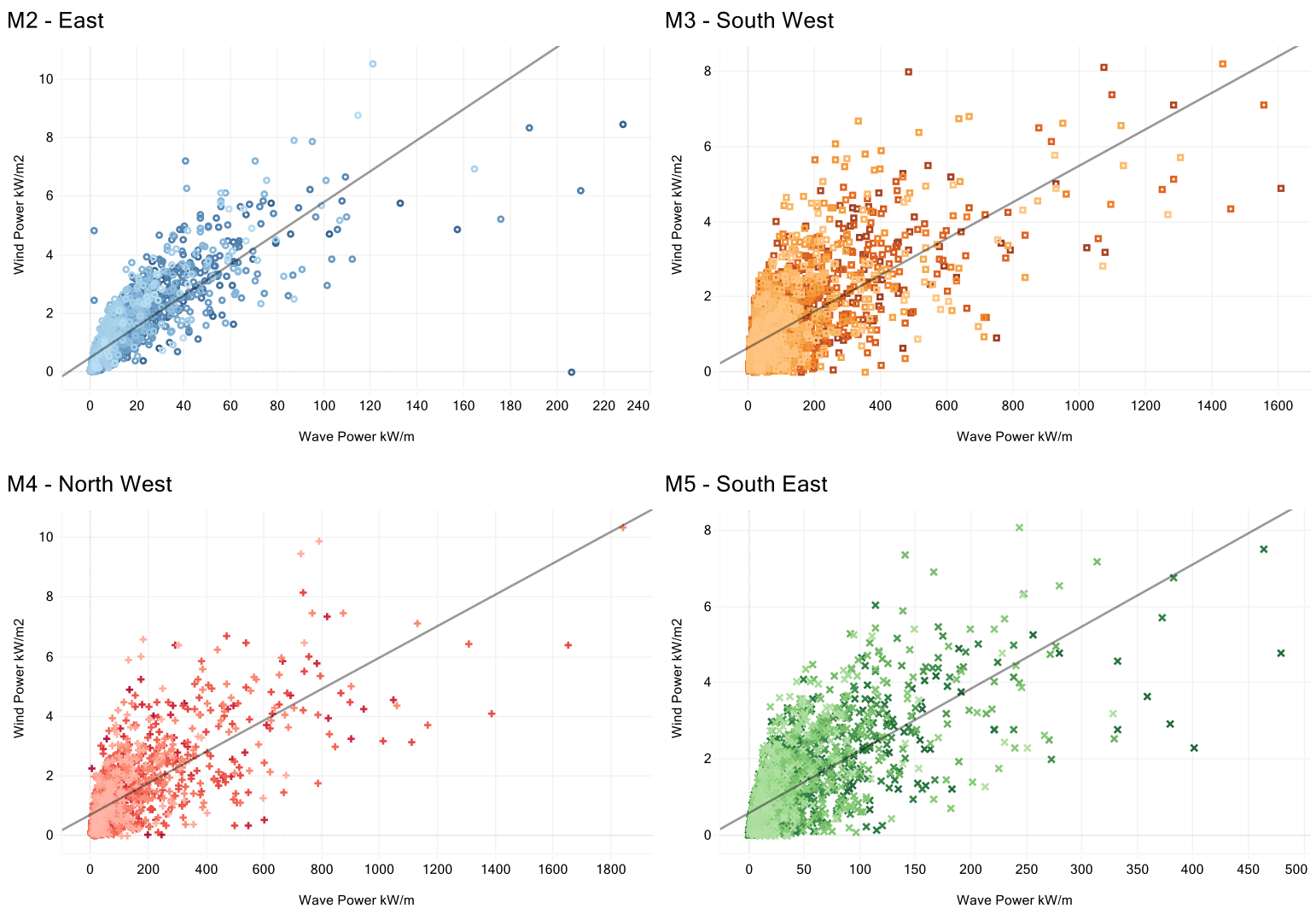

Figure 8: Scatter plots at zero time lag for potential wind and wave resource during the study period

The time series plots in Figure 14 and Figure 15 compare hourly observations for observed and expected sea states at the East and Northwest locations for comparison. In general, the correlation between observed and expected wave height shows better agreement than observed and expected wave period. The East shows good agreement for observed wave height and expected wave height, while the Northwest region shows much higher wave height observations than expected. Similarly, for the observed versus expected wave period the time series for the Northwest shows higher observations than those expected which may be the result of swells with lengthened periods of time. 
M4 Winter

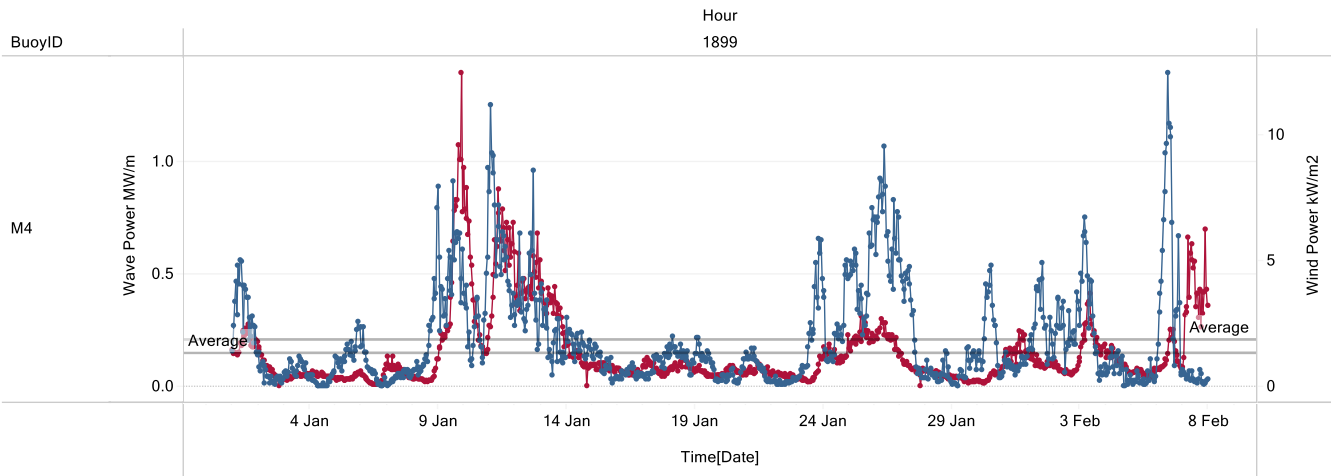

M2 Winter

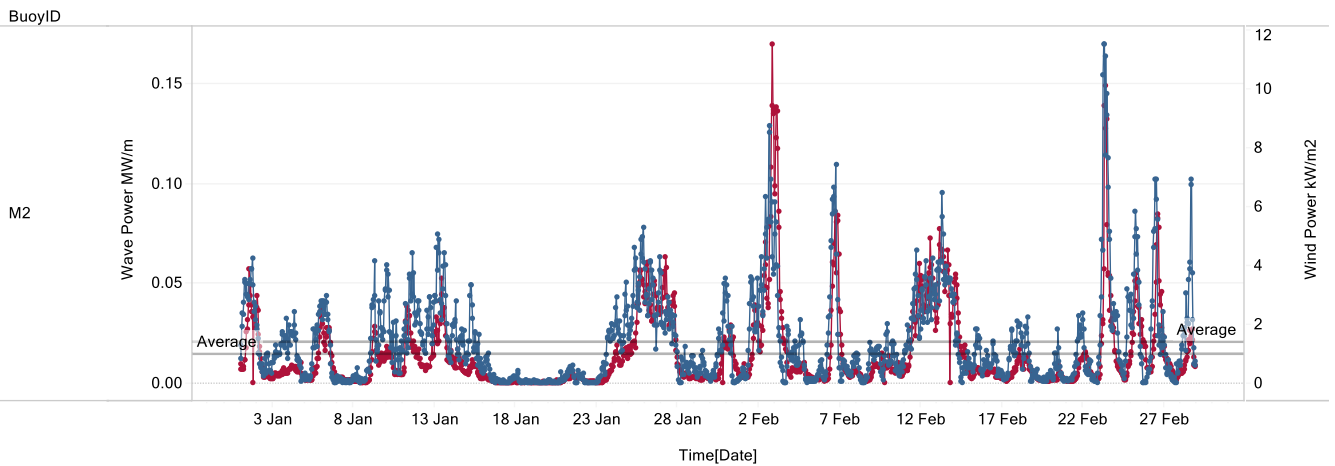

Figure 9: Time series plot of wind and wave power at offshore sites - Winter
Measure Names

Wind Power $\mathrm{kW} / \mathrm{m} 2$ 
BuoylD

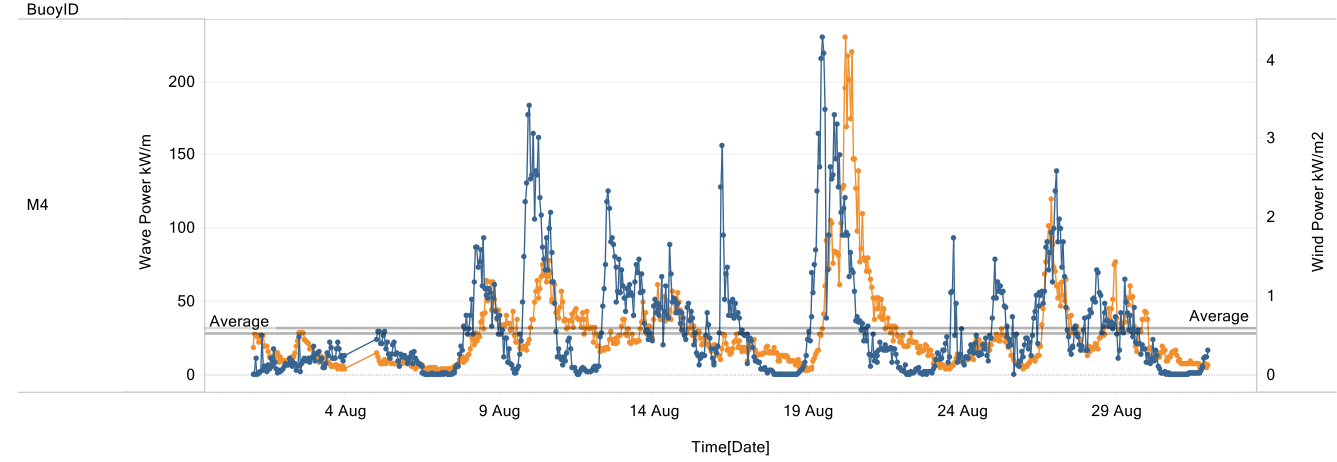

M2 Summer

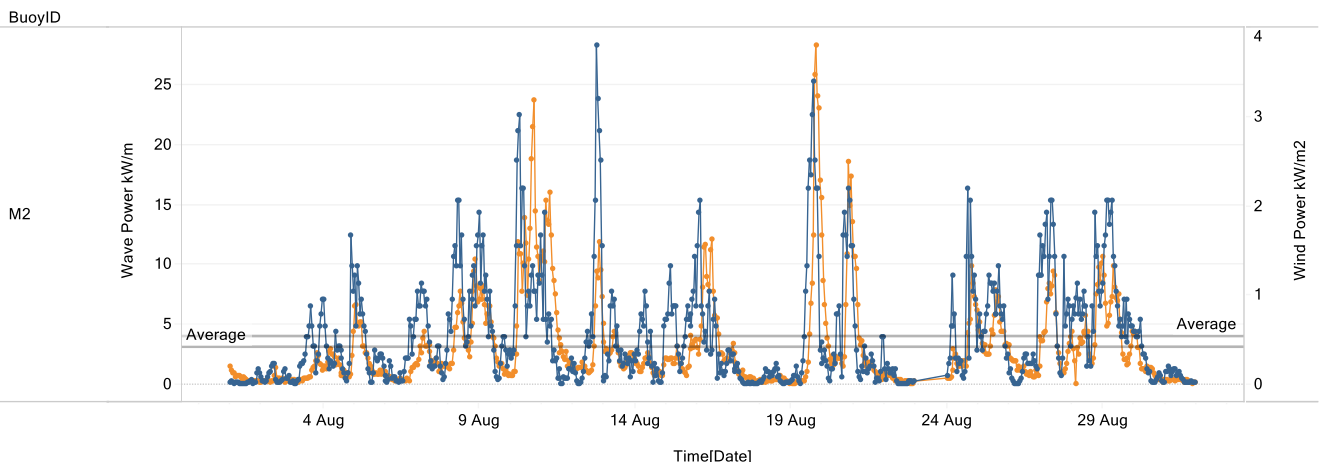

Figure 10: Time series plot of wind and wave power at offshore sites - Summer 




Figure 11: Decline of lag over time for each offshore location 


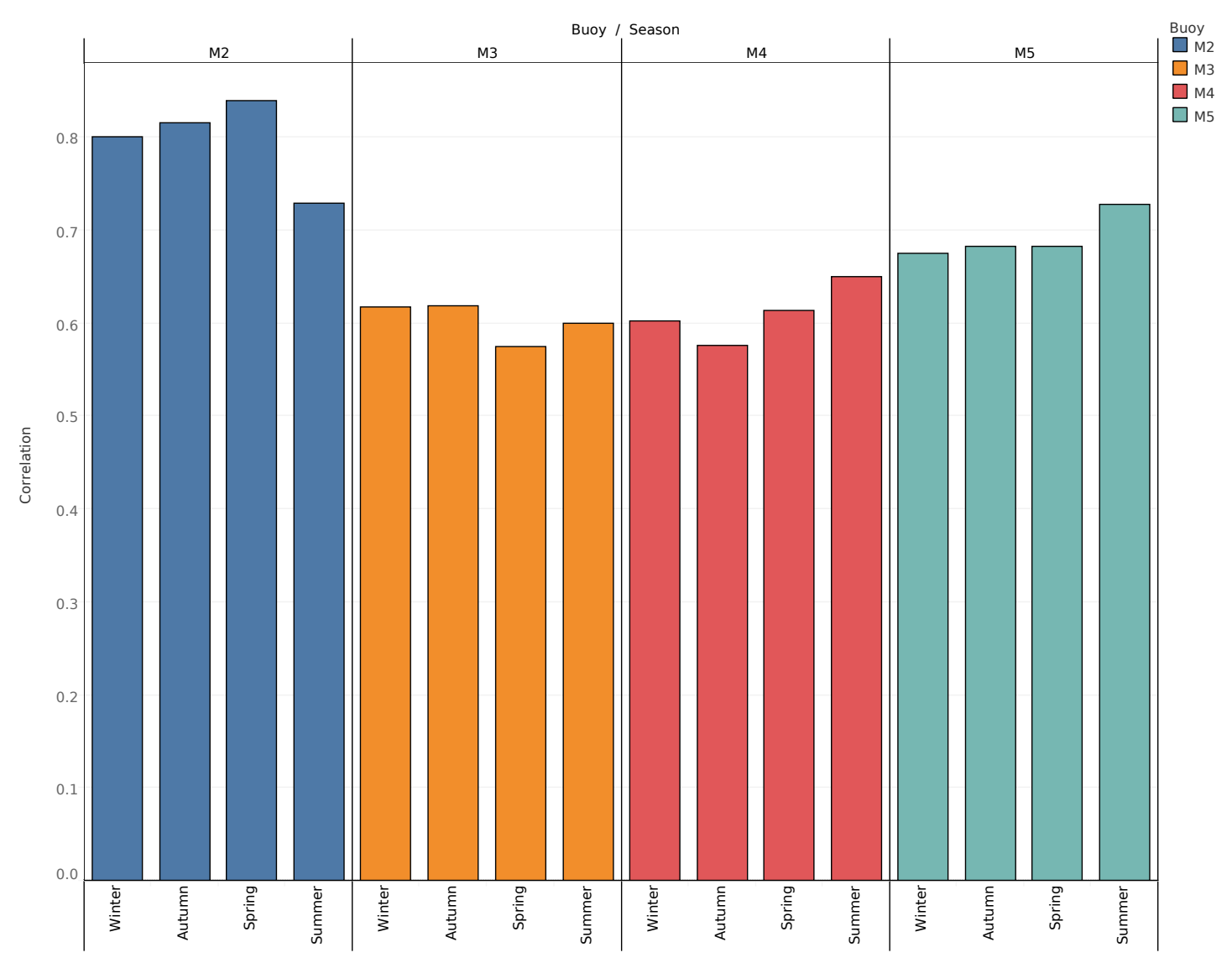

Figure 12: Correlation between observed and expected significant wave heights 


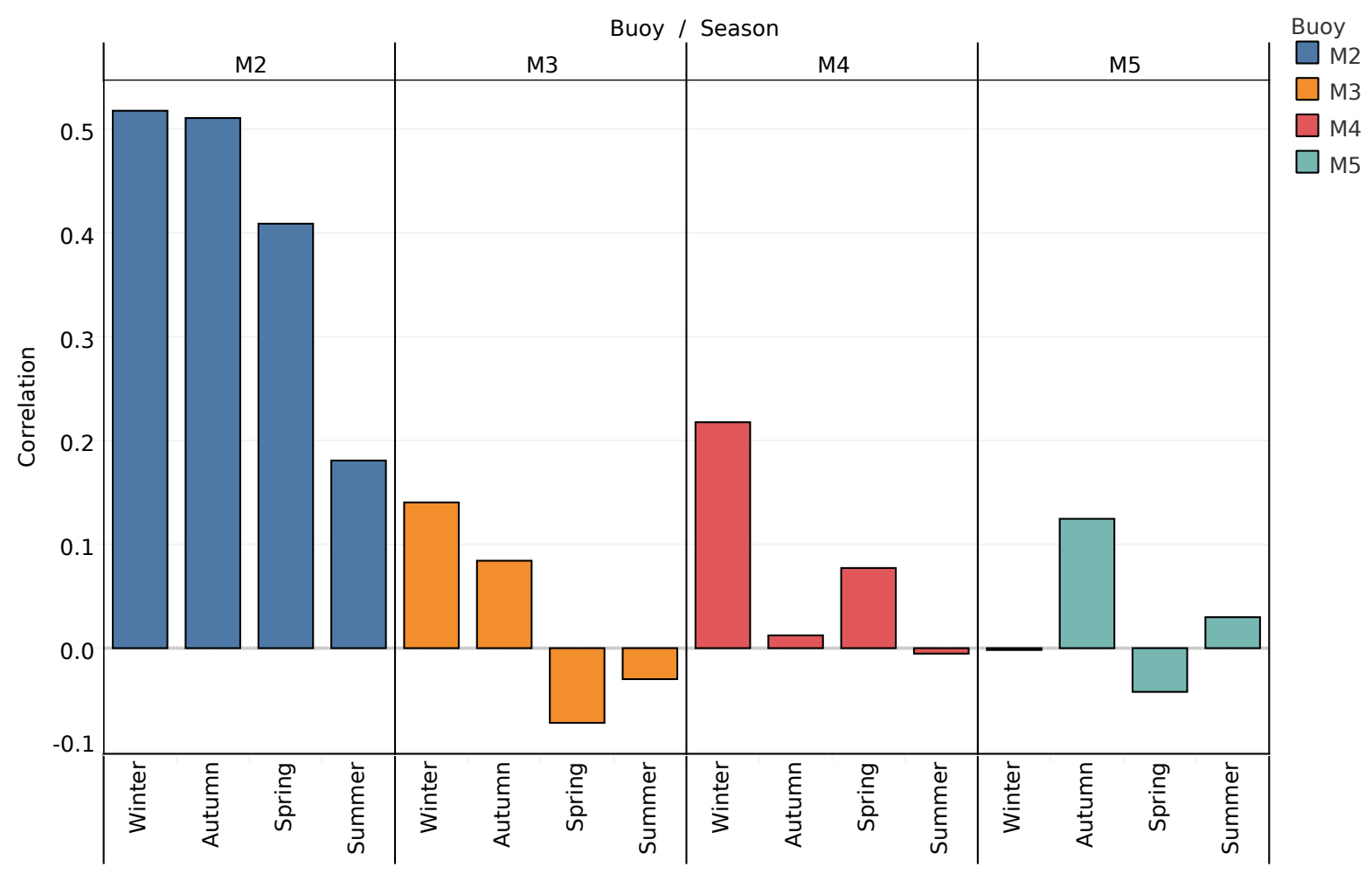

Figure 13: Correlation between observed and expected significant wave periods 

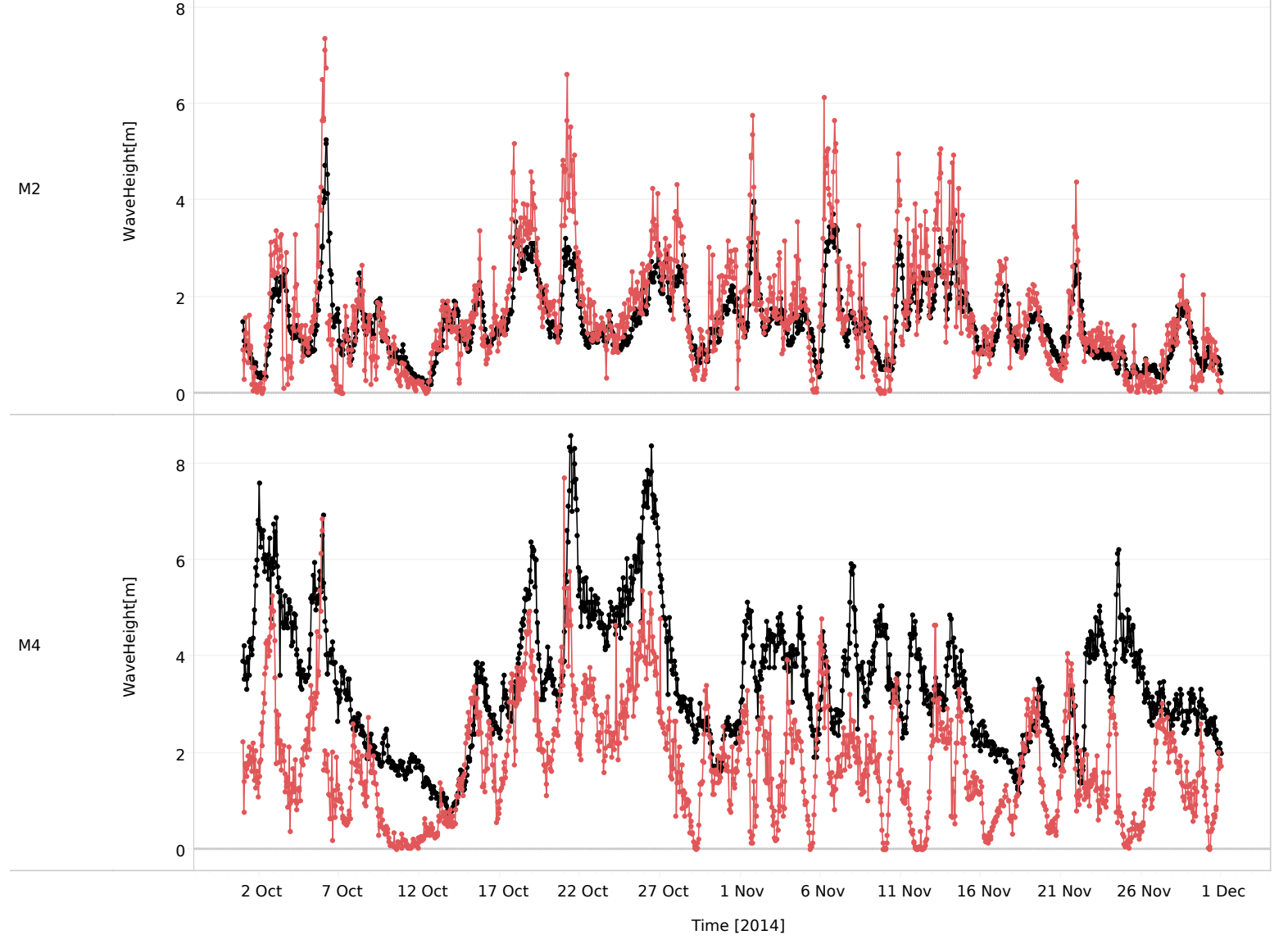

Figure 14: Observed and expected wave height at East coast (M2) and West coast (M4) 


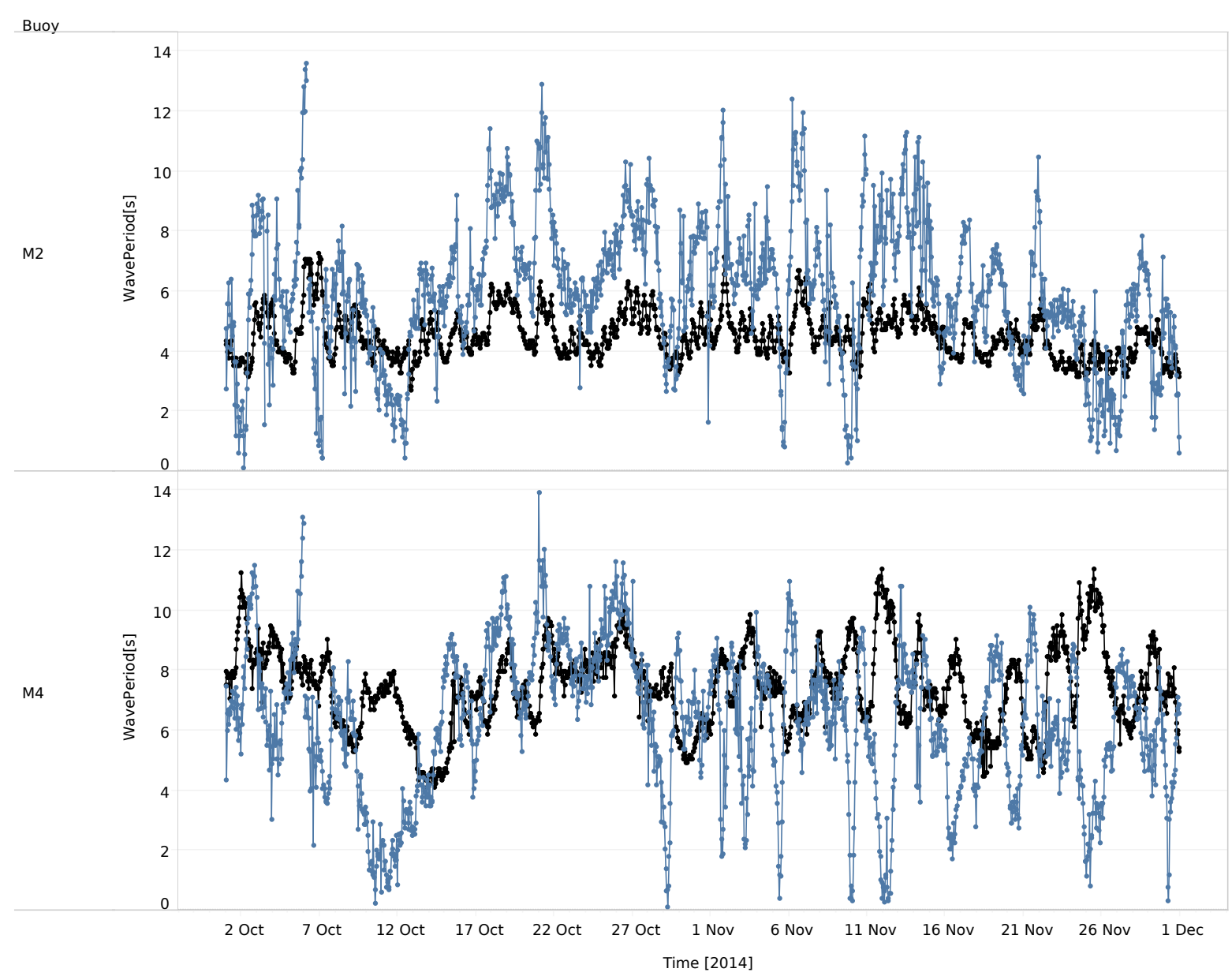

Figure 15: Observed and expected wave period at East coast (M2) and West coast (M4) 


\section{Discussion}

\subsection{Combining offshore wave and wind energy}

\subsubsection{Reduced intermittency}

The co-location of wind-wave farms has been suggested as a viable solution to the problem of renewable resource intermittency[22] and the possibility of periods of zero power production. Numerous studies have shown that wave peaks trail the wind peaks for the same weather systems $[23,24]$ and that wave power is more predictable than wind power [25]. Power output variability may be reduced by considering sites where there is a low correlation between both wind and wave resources. The identification of a low correlation between resources at a single site suggests that the peaks and troughs of each resource occur at different times and hence there is the potential to smooth power output. Chozas et al. [23] found that under three different scenarios of combined wind-wave farms, periods of zero power production were reduced. It was found that for a combined system, zero production dropped to $6 \%$ compared to $36 \%$ in a $100 \%$ wave system and $13 \%$ in a $100 \%$ wind system. Stoutenburg et al. [26] also found that combined farms would have 100 hours or less of zero power output per year when compared with 1000 hours for offshore wind alone or 200 hours for wave alone.

\subsubsection{Reduced costs and enlarged weather windows}

The installation of combined offshore wind turbines and WECs has the potential to reduce both capital and $\mathrm{O} \& \mathrm{M}$ costs $[24,27]$. This is particularly relevant when $65 \%$ of the total levelised costs of wave energy are associated with $\mathrm{O} \& \mathrm{M}$ costs [27]. Astariz et al. [28] found that combined wave-wind farms could reduce capital costs by between $12 \%$ and $14 \%$ and increase accessibility to wind farms by up to $82 \%$, reducing losses from maintenance delays by approximately $€ 250,000$ per year. Furthermore, WECs and the energy extraction they undertake modifies the local climate by reducing mean wave height. Combining both WECs and offshore wind turbines at a single site has the potential to reduce wave height, increasing the weather window for maintenance activities and reducing structural loads [27]. In the North Sea, a co-location study has shown the potential to reduce significant wave height by over $13.5 \%$ resulting in larger weather windows for $\mathrm{O} \& \mathrm{M}$ activities and hence lower shared costs [29].

\subsubsection{Co-location of wind and wave energy farms}

A limited number of studies have undertaken a correlation analysis between wind and wave energy sources to identify the temporal variability between sources at a given site. Kalogeri et al. [21] undertook an analysis of the offshore energy potential in Europe to identify areas favourable for combined wind and wave energy exploitation. The study used the results of atmospheric and wave modelling hindcast simulations (the MARINA database) for a period of ten years and identified sites where there was a low correlation between wind and wave power. The assessment found the Northwest coast of Europe to have the highest wind and wave power density. Areas controlled by the Atlantic swell had more merit for combined wind and wave resource than those dominated by local weather conditions. Belmullet on the Northwest coast of Ireland was identified as one of the most energy intense areas of Europe where the correlation between both resources was low with a stable seasonal variability. Cradden et al. [24] also used the results from the MARINA platform as a data source. This study found that the largest potential for combined resource was in the North and West of Europe, specifically off the coasts of Ireland and Scotland. Other studies have performed high-resolution long-term wave and wind hindcasts by dynamically downscaling from reanalysis datasets. Gallagher et al. [30] carried out a wave and wind hindcast for Ireland at a high spatial resolution. The study undertook a downscaling approach using ERA-Interim re-analysis dataset from the ECMWF. Four locations on the Irish coast were identified for nearshore co-located wind and wave farms. These locations were chosen based on three factors including accessibility, the low correlation between wind and wave energy and the energy resource available. The areas of interest were west of Malin Head, Donegal bay, the Dingle Peninsula and Southern locations such as Carnsore Point and Baltimore. Fusco et al. [10] followed a different methodology by considering raw data. The parameters considered were wind speed, wave period and significant wave height for a short three-year study period. The study concluded that there 
was an opportunity for wind-wave farms off the West and South coast of Ireland as the correlation between both resources was low in these areas.

\subsection{Potential for combining offshore wave and wind energy at Irish sites}

The present study has considered ten years of raw data for four offshore sites in Irish waters. In general, the wind energy resource is consistent offshore at all locations with averages ranging between $1170 \mathrm{~W} / \mathrm{m}^{2}$ and $1530 \mathrm{~W} / \mathrm{m}^{2}$. The highest averages are seen on the Northwest coast with an average of $1530 \mathrm{~W} / \mathrm{m}^{2}$ over the ten-year study period. The difference identified between the Northwest and the East coast wind resource is approximately $360 \mathrm{~W} / \mathrm{m}^{2}$. The average values identified here are consistent with those identified by in [9] which found averages ranging between 800 and $1600 \mathrm{~W} / \mathrm{m}^{2}$ between the West and East regions. The present study identified slightly higher seasonal means than [9], for example this study identified winter means ranging from $1800 \mathrm{~W} / \mathrm{m}^{2}$ to $2400 \mathrm{~W} / \mathrm{m}^{2}$ compared to winter means ranging from $1200 \mathrm{~W} / \mathrm{m}^{2}$ to $2000 \mathrm{~W} / \mathrm{m}^{2}$ in [9]. The discrepancy between the studies can be explained by the use of raw data versus modelled data and the difference in the reference height levels chosen for available wind power calculations. This study considered available wind power at 124-meter height rather than the 100-meter height considered in [9]. A height of 124 meters was chosen as this is the hub height of the turbines installed at the Arklow Bank offshore wind farm in the Irish Sea. The present study identified a pronounced difference in the wave resource between the Northwest and East coast of Ireland with an average difference of $120 \mathrm{~kW} / \mathrm{m}$. The East and Southeast coast have a particularly low wave resource with an average power of between 13 and $38 \mathrm{~kW} / \mathrm{m}$. These figures align with [9] which also found power levels in the range of $15-20 \mathrm{~kW} / \mathrm{m}$ on the Southern coast. Particularly high energy sea states have been identified on the Northwest coast with power levels above $250 \mathrm{~kW} / \mathrm{m}$, particularly in the winter season. The average wave power available in spring and summer is still significant at just under $120 \mathrm{~kW} / \mathrm{m}$ and $40 \mathrm{~kW} / \mathrm{m}$ respectively and may be more suitable for extraction using current WEC technologies.

\subsubsection{Comparison with other studies}

The present study has demonstrated that the largest power potential for wind and wave energy in Ireland is on the Northwest and Southwest coasts, particularly in winter. A moderate positive correlation was found between the wind and wave resource for the Northwest and Southwest regions with $R^{2}$ values ranging between 0.6-0.65 and a significant time lag of six hours. A very strong correlation was identified on the East coast $\left(R^{2}=0.8\right)$ with a minimal time lag of two hours between the resources. This suggests that M2 would not be a suitable location for a co-located offshore wind and wave farm. The comparison of observed wave parameters with expected wave parameters from observed wind speed measurements indicated the wave energy generated on the Northwest coast originated from North Atlantic swells rather than local wind waves, which corresponded with the findings of the initial correlation analysis.

At a high level these findings are in agreement with $[9,10]$, both of which observed modest correlations on the West coast and high correlations on the East coast. However, this study considers a longer time series of raw data enhancing the wind and wave power estimates at each location and analyses an additional offshore location off the Northwest coast (M4) not previously considered in the literature. The present study provides a more accurate analysis of the wave power potential by considering the irregular nature of waves through 10 years of raw data, previous studies have used regular wave theory [10] or modelled data [9]. This study also provides inter-annual and seasonal analyses of the correlations and lags at each site. A noteworthy discrepancy observed between this study and [10] is the significant difference observed between the correlation and lag at M1 (West) in [10] and M4 (Northwest) in this study. For instance, in [10] a low correlation coefficient of 0.15 at time lag zero (instantaneous correlation), with a maximum correlation of 0.35 at a time lag of ten hours is reported at M1. The present study found a higher correlation coefficient of 0.55 at time lag zero, with a maximum correlation of 0.61 at a time lag of six hours at M4. The higher correlation and lower time lag identified in this study for the Northwest buoy would suggest that the local wind conditions at M4 are more influential on the wave formation than those at M1 and hence less suitable for combined wind and wave resource. Additionally, the present study identified higher seasonal correlation coefficients for the M2, M3 and M5 locations to those observed in [10]. This may be 
the result of the inter-annual variability of correlation coefficients identified in this study (see Appendix C (Tables C.7- C.10).

The present study has considered a large dataset of ten years. The large raw dataset has allowed this study to undertake inter-annual and seasonal analyses of the cross-correlation between both resources across Ireland. The results of these analyses show that while favourable low correlation values and long-time lags exist in locations such as M4 and M3, an unstable behaviour exists where both correlations and lags are inconsistent from year to year with high variability. Appendix C (Tables C.7- C.10) illustrates the unstable behaviour at all locations except for M2 where there is low variability of correlations and lags inter-annually. For example, M4 demonstrates a mean annual correlation of 0.4 in 2017 and 0.6 in 2011. On the contrary M2 demonstrates an unchanging pattern where correlations are consistently above 0.7 and time lags are stable ranging from 2-3 hours.

\section{Conclusion}

Ireland has significant wind and wave resources. In addition to estimating the wind and wave energy resource, this study focused on assessing the correlation between wind and wave resources, for four different offshore locations around Ireland to investigate if the variability of one resource could complement the variability of another resulting in a smoother power output.

While the average wind power is generally consistent at different offshore locations, large variance can be seen in the wave resource. The analysis suggests the highest energy potential to be in the Northwest (M4) and Southwest (M3) of Ireland, where there is a significant amount of wave resource (power levels above $200 \mathrm{~kW} / \mathrm{m}$ in winter and approximately $40 \mathrm{~kW} / \mathrm{m}$ in summer). For M4 low correlation coefficients were identified inter-annually between wind and wave parameters with an average maximum $R^{2}$ value of 0.61 at a time lag of 6 hours for the ten-year study period. Seasonal cross correlations also displayed low $R^{2}$ values of between $0.51-0.55$ for all seasons with a lag of 6 hours. Similar findings were identified for M3 where correlations were lower during the spring and summer months to those identified at M4. These results indicate that the waves generated on the Northwest and Southwest coast are from swell systems in the Atlantic Ocean rather than local wind conditions. Significant temporal lags are observed between both resources where peaks and troughs of both profiles occur at different periods throughout the day. The discrepancies between these two resources offer a potential solution to two of the biggest issues associated with single source renewable technologies - their variability and zero power production periods.

This study also identified that co-located wind wave farms would not be suitable across all areas of Ireland. A high correlation was observed between both resources, particularly off the East coast (M2) with an average maximum $R^{2}$ value of 0.8 at a time lag of 2.4 hours for the ten-year study period. Additionally, the observed wave parameters and expected wave parameters calculated from the raw data showed good agreement indicating the waves generated at M2 were strongly aligned with local wind conditions. This agreement would suggest that the combination of both resources at a single site on the East coast would not significantly reduce the variability of power output or reduce the zero power production periods.

The study has noted that while favourable low correlation values and long-time lags exist in locations off the Northwest and Southwest coast there is high inter-annual variability. This variability is present at all sites except for the East where there is low variability of correlations and lags inter-annually.

\section{Appendix A. Data considered}




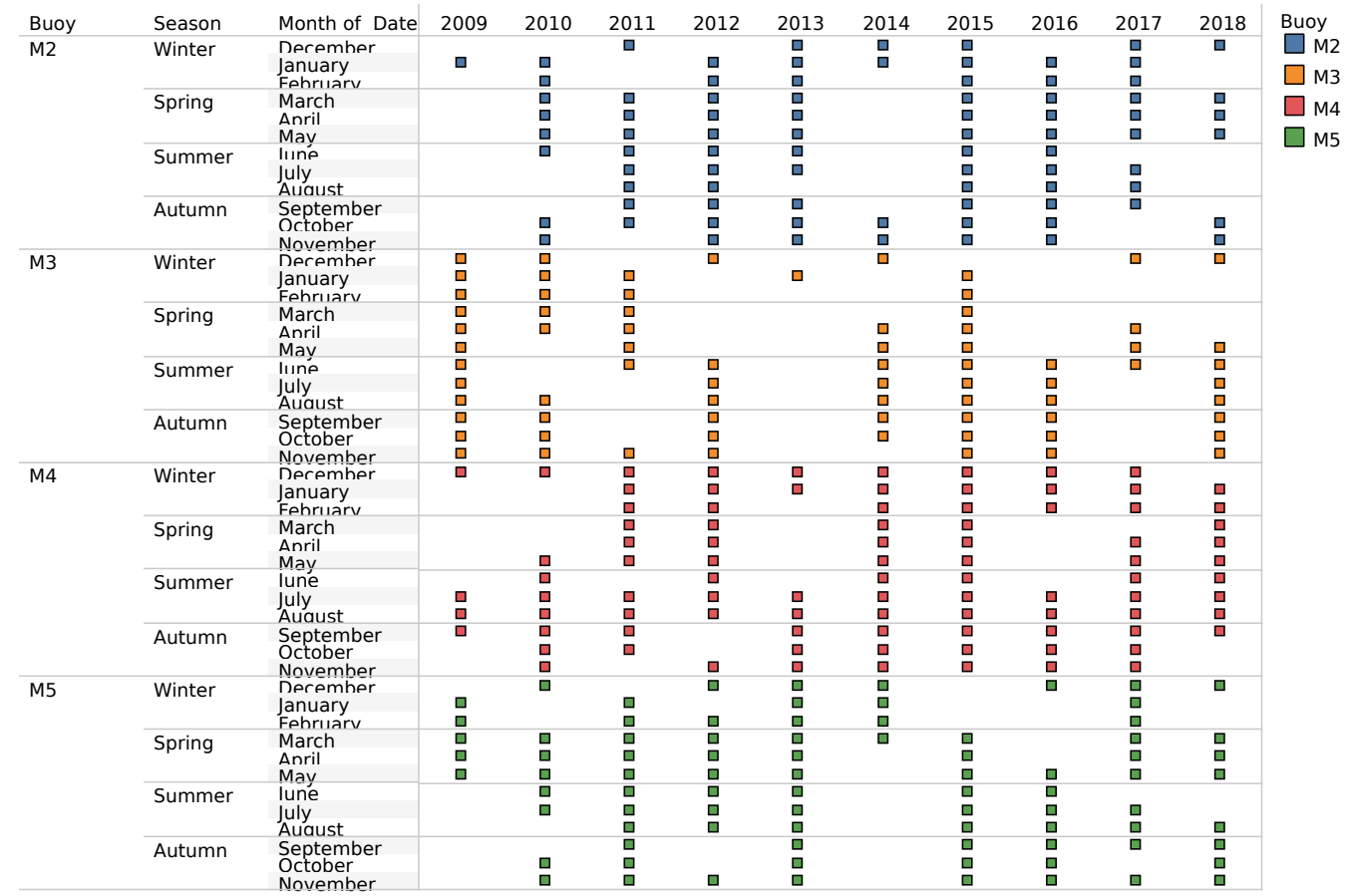

Figure A.16: Wind data considered for each location

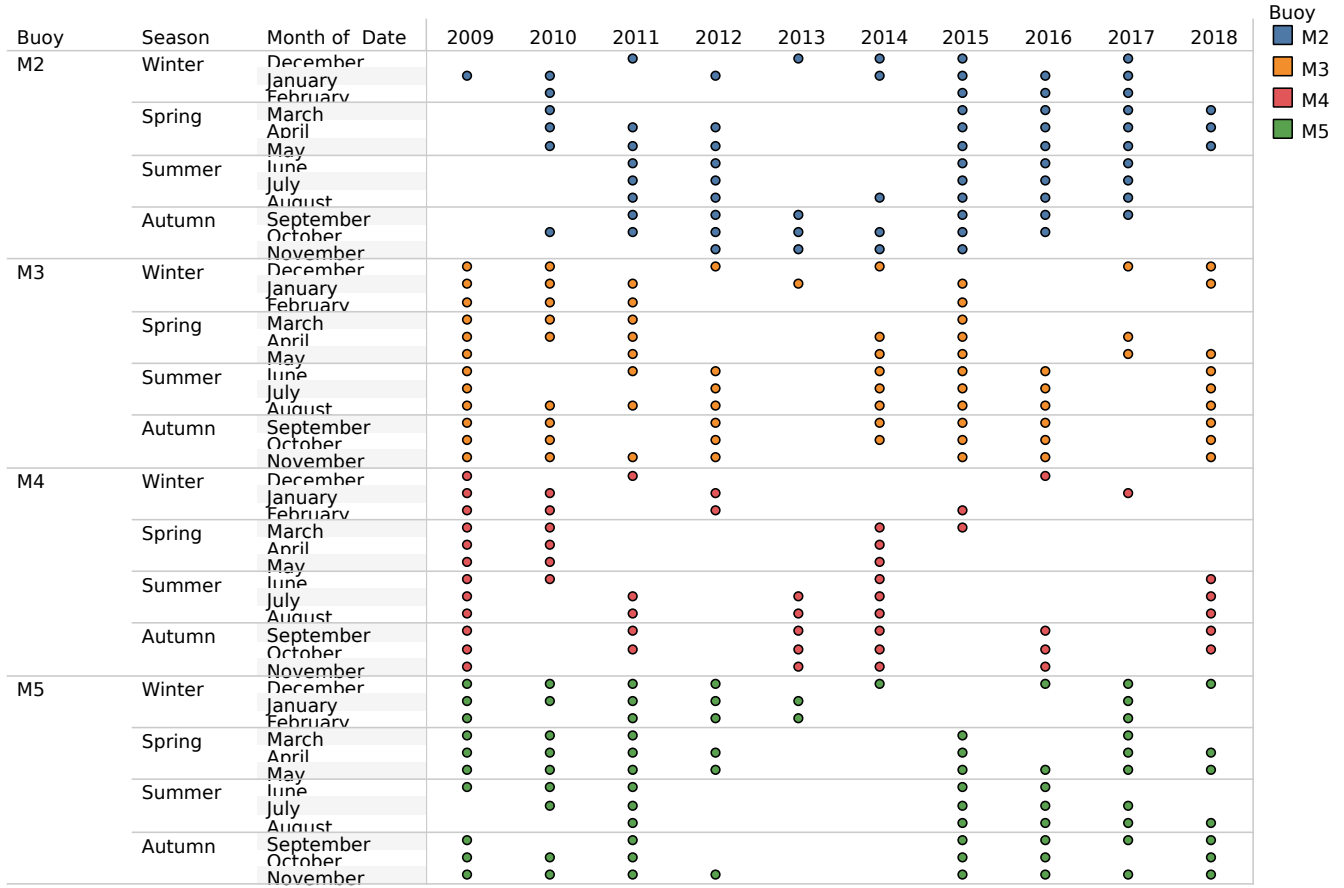

Figure A.17: Wave data considered for each location 


\section{Appendix B. Stationarity test}

\begin{tabular}{ll} 
Dickey-Fuller test (ADF(stationary) / k: $19 / 0.750998323135042):$ & \\
\hline Tau (Observed value) & -9.969 \\
Tau (Critical value) & -3.406 \\
p-value (one-tailed) & $<0.0001$ \\
alpha & 0.05 \\
\hline
\end{tabular}

Test interpretation:

$H_{0}$ : There is a unit root for the series.

$H_{a}$ : There is no unit root for the series. The series is stationary.

As the computed p-value is lower than the significance level alpha $=0.05$, one should reject the null hypothesis $H_{0}$, and accept the alternative hypothesis $H_{a}$.

Appendix C. Annual and seasonal correlations for study period 
Table C.7: Annual correlations for M2 location

$\begin{array}{lllllllllll}\text { Lag (h) } & 2009 & 2010 & 2011 & 2012 & 2013 & 2014 & 2015 & 2016 & 2017 & 2018 \\ 0 & 0.76 & 0.75 & 0.79 & 0.74 & 0.71 & 0.67 & 0.76 & 0.78 & 0.73 & 0.81 \\ 1 & 0.80 & 0.78 & 0.82 & 0.78 & 0.75 & 0.72 & 0.80 & 0.82 & 0.77 & 0.82 \\ 2 & 0.81 & 0.80 & 0.84 & 0.79 & 0.77 & 0.74 & 0.82 & 0.84 & 0.78 & 0.82 \\ 3 & 0.80 & 0.80 & 0.83 & 0.79 & 0.77 & 0.74 & 0.82 & 0.84 & 0.75 & 0.82 \\ 4 & 0.78 & 0.79 & 0.82 & 0.78 & 0.75 & 0.73 & 0.79 & 0.83 & 0.72 & 0.82 \\ 5 & 0.76 & 0.76 & 0.81 & 0.76 & 0.71 & 0.70 & 0.77 & 0.81 & 0.68 & 0.82 \\ 6 & 0.74 & 0.72 & 0.78 & 0.73 & 0.66 & 0.66 & 0.74 & 0.79 & 0.65 & 0.82 \\ 7 & 0.71 & 0.68 & 0.76 & 0.70 & 0.62 & 0.63 & 0.71 & 0.76 & 0.62 & 0.82 \\ 8 & 0.68 & 0.63 & 0.72 & 0.67 & 0.59 & 0.60 & 0.68 & 0.72 & 0.59 & 0.81 \\ 9 & 0.66 & 0.59 & 0.68 & 0.64 & 0.56 & 0.56 & 0.65 & 0.68 & 0.56 & 0.80 \\ 10 & 0.63 & 0.54 & 0.65 & 0.60 & 0.54 & 0.52 & 0.62 & 0.64 & 0.52 & 0.78 \\ 11 & 0.61 & 0.49 & 0.61 & 0.57 & 0.51 & 0.48 & 0.58 & 0.60 & 0.48 & 0.75 \\ 12 & 0.57 & 0.46 & 0.57 & 0.53 & 0.48 & 0.44 & 0.55 & 0.56 & 0.45 & 0.72 \\ 13 & 0.55 & 0.42 & 0.53 & 0.50 & 0.45 & 0.41 & 0.52 & 0.53 & 0.41 & 0.69 \\ 14 & 0.51 & 0.39 & 0.50 & 0.46 & 0.42 & 0.37 & 0.50 & 0.49 & 0.38 & 0.67 \\ 15 & 0.49 & 0.36 & 0.48 & 0.43 & 0.39 & 0.34 & 0.47 & 0.47 & 0.35 & 0.64 \\ 16 & 0.46 & 0.34 & 0.45 & 0.39 & 0.36 & 0.32 & 0.46 & 0.44 & 0.33 & 0.62 \\ 17 & 0.43 & 0.32 & 0.44 & 0.36 & 0.33 & 0.29 & 0.44 & 0.43 & 0.31 & 0.60 \\ 18 & 0.40 & 0.31 & 0.42 & 0.34 & 0.31 & 0.28 & 0.42 & 0.41 & 0.30 & 0.59 \\ 19 & 0.38 & 0.29 & 0.41 & 0.32 & 0.28 & 0.26 & 0.41 & 0.40 & 0.28 & 0.58 \\ 20 & 0.35 & 0.27 & 0.40 & 0.30 & 0.27 & 0.25 & 0.40 & 0.39 & 0.27 & 0.57\end{array}$

Table C.8: Annual correlations for M3 location

\begin{tabular}{rrrrrrrrrrrr} 
Lag & & 2009 & 2010 & 2011 & 2012 & 2013 & 2014 & 2015 & 2016 & 2017 & 2018 \\
& 0 & 0.57 & 0.51 & 0.52 & 0.49 & 0.55 & 0.53 & 0.64 & 0.52 & 0.68 & 0.56 \\
1 & 0.59 & 0.54 & 0.53 & 0.52 & 0.57 & 0.54 & 0.66 & 0.54 & 0.71 & 0.59 \\
\hline 2 & 0.60 & 0.56 & 0.55 & 0.53 & 0.59 & 0.55 & 0.67 & 0.56 & 0.73 & 0.62 \\
3 & 0.60 & 0.58 & 0.55 & 0.55 & 0.60 & 0.56 & 0.69 & 0.57 & 0.75 & 0.64 \\
4 & 0.61 & 0.59 & 0.56 & 0.56 & 0.62 & 0.57 & 0.69 & 0.57 & 0.75 & 0.66 \\
5 & 0.62 & 0.60 & 0.56 & 0.56 & 0.62 & 0.58 & 0.70 & 0.57 & 0.75 & 0.67 \\
6 & 0.61 & 0.60 & 0.56 & 0.56 & 0.63 & 0.58 & 0.71 & 0.57 & 0.74 & 0.68 \\
7 & 0.61 & 0.60 & 0.55 & 0.56 & 0.62 & 0.57 & 0.71 & 0.56 & 0.73 & 0.69 \\
8 & 0.61 & 0.60 & 0.55 & 0.55 & 0.62 & 0.57 & 0.71 & 0.56 & 0.72 & 0.69 \\
9 & 0.60 & 0.59 & 0.54 & 0.54 & 0.62 & 0.57 & 0.70 & 0.55 & 0.70 & 0.69 \\
10 & 0.60 & 0.58 & 0.54 & 0.53 & 0.60 & 0.57 & 0.70 & 0.55 & 0.68 & 0.68 \\
11 & 0.60 & 0.57 & 0.53 & 0.53 & 0.59 & 0.57 & 0.69 & 0.54 & 0.66 & 0.68 \\
12 & 0.59 & 0.57 & 0.53 & 0.52 & 0.57 & 0.56 & 0.69 & 0.54 & 0.63 & 0.67 \\
13 & 0.59 & 0.55 & 0.52 & 0.51 & 0.55 & 0.56 & 0.68 & 0.53 & 0.62 & 0.66 \\
14 & 0.58 & 0.54 & 0.51 & 0.50 & 0.54 & 0.56 & 0.67 & 0.52 & 0.60 & 0.65 \\
15 & 0.58 & 0.53 & 0.50 & 0.49 & 0.51 & 0.55 & 0.67 & 0.51 & 0.58 & 0.63 \\
16 & 0.58 & 0.52 & 0.50 & 0.47 & 0.51 & 0.54 & 0.66 & 0.50 & 0.56 & 0.62 \\
17 & 0.57 & 0.51 & 0.49 & 0.46 & 0.48 & 0.54 & 0.65 & 0.48 & 0.53 & 0.61 \\
18 & 0.56 & 0.49 & 0.48 & 0.45 & 0.46 & 0.53 & 0.64 & 0.46 & 0.51 & 0.59 \\
19 & 0.56 & 0.47 & 0.47 & 0.44 & 0.44 & 0.52 & 0.63 & 0.44 & 0.49 & 0.57 \\
20 & 0.55 & 0.46 & 0.46 & 0.42 & 0.41 & 0.51 & 0.62 & 0.43 & 0.46 & 0.56
\end{tabular}


Table C.9: Annual correlations for M4 location

$\begin{array}{llllllllllll}\text { Lag (h) } & 2009 & 2010 & 2011 & 2012 & 2013 & 2014 & 2015 & 2016 & 2017 & 2018 \\ 0 & 0.53 & 0.56 & 0.66 & 0.55 & 0.53 & 0.53 & 0.49 & 0.54 & 0.44 & 0.55 \\ 1 & 0.56 & 0.59 & 0.68 & 0.58 & 0.55 & 0.54 & 0.52 & 0.56 & 0.46 & 0.58 \\ 2 & 0.59 & 0.60 & 0.70 & 0.59 & 0.57 & 0.56 & 0.55 & 0.57 & 0.48 & 0.62 \\ 3 & 0.60 & 0.61 & 0.71 & 0.60 & 0.59 & 0.56 & 0.57 & 0.59 & 0.50 & 0.64 \\ 4 & 0.61 & 0.62 & 0.71 & 0.60 & 0.61 & 0.57 & 0.59 & 0.60 & 0.52 & 0.66 \\ 5 & 0.61 & 0.61 & 0.72 & 0.60 & 0.61 & 0.57 & 0.60 & 0.61 & 0.53 & 0.67 \\ 6 & 0.61 & 0.61 & 0.71 & 0.61 & 0.62 & 0.57 & 0.60 & 0.62 & 0.53 & 0.68 \\ 7 & 0.61 & 0.60 & 0.70 & 0.60 & 0.62 & 0.57 & 0.61 & 0.63 & 0.53 & 0.68 \\ 8 & 0.60 & 0.59 & 0.70 & 0.59 & 0.62 & 0.57 & 0.61 & 0.64 & 0.53 & 0.69 \\ 9 & 0.60 & 0.58 & 0.68 & 0.59 & 0.62 & 0.57 & 0.61 & 0.65 & 0.52 & 0.68 \\ 10 & 0.60 & 0.57 & 0.67 & 0.59 & 0.62 & 0.57 & 0.61 & 0.65 & 0.51 & 0.67 \\ 11 & 0.60 & 0.56 & 0.65 & 0.58 & 0.62 & 0.57 & 0.62 & 0.65 & 0.49 & 0.66 \\ 12 & 0.59 & 0.55 & 0.64 & 0.57 & 0.62 & 0.57 & 0.61 & 0.65 & 0.49 & 0.65 \\ 13 & 0.59 & 0.54 & 0.62 & 0.56 & 0.61 & 0.57 & 0.61 & 0.65 & 0.48 & 0.64 \\ 14 & 0.57 & 0.53 & 0.61 & 0.55 & 0.60 & 0.56 & 0.59 & 0.65 & 0.47 & 0.62 \\ 15 & 0.56 & 0.53 & 0.60 & 0.54 & 0.59 & 0.56 & 0.58 & 0.64 & 0.48 & 0.60 \\ 16 & 0.54 & 0.52 & 0.58 & 0.53 & 0.57 & 0.56 & 0.57 & 0.65 & 0.47 & 0.58 \\ 17 & 0.53 & 0.52 & 0.57 & 0.52 & 0.56 & 0.56 & 0.55 & 0.64 & 0.48 & 0.57 \\ 18 & 0.51 & 0.51 & 0.56 & 0.51 & 0.55 & 0.55 & 0.54 & 0.64 & 0.49 & 0.55 \\ 19 & 0.49 & 0.50 & 0.55 & 0.50 & 0.54 & 0.55 & 0.53 & 0.62 & 0.49 & 0.54 \\ 20 & 0.48 & 0.50 & 0.53 & 0.48 & 0.52 & 0.54 & 0.52 & 0.61 & 0.48 & 0.52\end{array}$

Table C.10: Annual correlations for M5 location

\begin{tabular}{lllllllllll|l} 
Lag (h) & 2009 & 2010 & 2011 & 2012 & 2013 & 2014 & 2015 & 2016 & 2017 & 2018 \\
0 & 0.51 & 0.61 & 0.55 & 0.47 & 0.62 & 0.73 & 0.69 & 0.59 & 0.43 & 0.54 \\
1 & 0.54 & 0.64 & 0.58 & 0.50 & 0.66 & 0.76 & 0.72 & 0.61 & 0.46 & 0.58 \\
2 & 0.57 & 0.66 & 0.59 & 0.52 & 0.67 & 0.78 & 0.75 & 0.63 & 0.48 & 0.61 \\
3 & 0.58 & 0.68 & 0.60 & 0.53 & 0.68 & 0.78 & 0.76 & 0.63 & 0.48 & 0.62 \\
4 & 0.58 & 0.69 & 0.60 & 0.53 & 0.69 & 0.79 & 0.77 & 0.63 & 0.48 & 0.64 \\
5 & 0.58 & 0.69 & 0.60 & 0.52 & 0.68 & 0.79 & 0.77 & 0.63 & 0.48 & 0.64 \\
6 & 0.57 & 0.68 & 0.60 & 0.50 & 0.67 & 0.78 & 0.75 & 0.62 & 0.47 & 0.64 \\
7 & 0.57 & 0.66 & 0.59 & 0.49 & 0.66 & 0.77 & 0.74 & 0.61 & 0.46 & 0.64 \\
8 & 0.56 & 0.65 & 0.58 & 0.48 & 0.65 & 0.77 & 0.72 & 0.59 & 0.45 & 0.63 \\
9 & 0.56 & 0.63 & 0.57 & 0.47 & 0.62 & 0.75 & 0.70 & 0.57 & 0.43 & 0.62 \\
10 & 0.55 & 0.61 & 0.56 & 0.46 & 0.61 & 0.73 & 0.68 & 0.55 & 0.41 & 0.62 \\
11 & 0.54 & 0.59 & 0.55 & 0.45 & 0.59 & 0.71 & 0.66 & 0.53 & 0.40 & 0.60 \\
12 & 0.53 & 0.57 & 0.53 & 0.43 & 0.56 & 0.69 & 0.64 & 0.51 & 0.38 & 0.59 \\
13 & 0.53 & 0.55 & 0.52 & 0.41 & 0.54 & 0.67 & 0.62 & 0.49 & 0.36 & 0.59 \\
14 & 0.52 & 0.54 & 0.51 & 0.39 & 0.51 & 0.65 & 0.61 & 0.47 & 0.34 & 0.59 \\
15 & 0.50 & 0.52 & 0.50 & 0.38 & 0.50 & 0.63 & 0.59 & 0.44 & 0.33 & 0.58 \\
16 & 0.49 & 0.50 & 0.49 & 0.36 & 0.48 & 0.61 & 0.58 & 0.42 & 0.32 & 0.57 \\
17 & 0.48 & 0.49 & 0.48 & 0.34 & 0.47 & 0.59 & 0.57 & 0.40 & 0.31 & 0.55 \\
18 & 0.47 & 0.47 & 0.47 & 0.32 & 0.45 & 0.57 & 0.56 & 0.38 & 0.30 & 0.53 \\
19 & 0.46 & 0.45 & 0.46 & 0.30 & 0.44 & 0.55 & 0.55 & 0.36 & 0.29 & 0.51 \\
20 & 0.45 & 0.43 & 0.45 & 0.29 & 0.43 & 0.53 & 0.54 & 0.34 & 0.28 & 0.49 \\
\hline & & & & & & & & & 0.53
\end{tabular}


Table C.11: Seasonal correlations for M2 location

$\begin{array}{lllll}\begin{array}{l}\text { Cross Correlations } \\ \text { Lag }(\mathrm{h})\end{array} & \text { Autumn } & \text { Spring } & \text { Summer } & \text { Winter } \\ 0 & 0.74 & 0.76 & 0.62 & 0.71 \\ 1 & 0.78 & 0.78 & 0.67 & 0.75 \\ 2 & 0.80 & 0.79 & 0.70 & 0.76 \\ 3 & 0.79 & 0.79 & 0.70 & 0.76 \\ 4 & 0.77 & 0.78 & 0.68 & 0.74 \\ 5 & 0.74 & 0.76 & 0.66 & 0.71 \\ 6 & 0.70 & 0.75 & 0.62 & 0.68 \\ 7 & 0.66 & 0.73 & 0.59 & 0.65 \\ 8 & 0.62 & 0.70 & 0.55 & 0.62 \\ 9 & 0.57 & 0.68 & 0.52 & 0.59 \\ 10 & 0.53 & 0.64 & 0.48 & 0.55\end{array}$

Table C.12: Seasonal correlations for M3 location

$\begin{array}{lllll}\begin{array}{l}\text { Cross Correlations } \\ \text { Lag }(\mathrm{h})\end{array} & \text { Autumn } & \text { Spring } & \text { Summer } & \text { Winter } \\ 0 & 0.55 & 0.49 & 0.53 & 0.54 \\ 1 & 0.58 & 0.52 & 0.55 & 0.56 \\ 2 & 0.60 & 0.53 & 0.58 & 0.58 \\ 3 & 0.62 & 0.55 & 0.59 & 0.59 \\ 4 & 0.63 & 0.55 & 0.60 & 0.60 \\ 5 & 0.63 & 0.56 & 0.60 & 0.61 \\ 6 & 0.63 & 0.56 & 0.60 & 0.61 \\ 7 & 0.63 & 0.56 & 0.60 & 0.61 \\ 8 & 0.62 & 0.55 & 0.59 & 0.61 \\ 9 & 0.61 & 0.55 & 0.57 & 0.61 \\ 10 & 0.60 & 0.54 & 0.56 & 0.60\end{array}$

Table C.13: Seasonal correlations for M4 location

$\begin{array}{lllll}\begin{array}{l}\text { Cross Correlations } \\ \text { Lag }(\mathrm{h})\end{array} & \text { Autumn } & \text { Spring } & \text { Summer } & \text { Winter } \\ 0 & 0.48 & 0.54 & 0.55 & 0.51 \\ 1 & 0.51 & 0.56 & 0.58 & 0.53 \\ 2 & 0.53 & 0.59 & 0.60 & 0.55 \\ 3 & 0.55 & 0.60 & 0.62 & 0.56 \\ 4 & 0.56 & 0.62 & 0.63 & 0.57 \\ 5 & 0.56 & 0.62 & 0.64 & 0.57 \\ 6 & 0.57 & 0.63 & 0.64 & 0.57 \\ 7 & 0.57 & 0.63 & 0.64 & 0.57 \\ 8 & 0.57 & 0.63 & 0.64 & 0.57 \\ 9 & 0.57 & 0.63 & 0.64 & 0.56 \\ 10 & 0.56 & 0.62 & 0.63 & 0.56\end{array}$

Table C.14: Seasonal correlations for M5 location

$\begin{array}{lllll}\begin{array}{l}\text { Cross Correlations } \\ \text { Lag }(\mathrm{h})\end{array} & \text { Autumn } & \text { Spring } & \text { Summer } & \text { Winter } \\ 0 & 0.47 & 0.57 & 0.63 & 0.52 \\ 1 & 0.51 & 0.60 & 0.65 & 0.55 \\ 2 & 0.53 & 0.62 & 0.66 & 0.57 \\ 3 & 0.55 & 0.63 & 0.66 & 0.58 \\ 4 & 0.55 & 0.64 & 0.66 & 0.59 \\ 5 & 0.55 & 0.64 & 0.64 & 0.59 \\ 6 & 0.54 & 0.63 & 0.63 & 0.59 \\ 7 & 0.53 & 0.62 & 0.61 & 0.58 \\ 8 & 0.51 & 0.61 & 0.59 & 0.57 \\ 9 & 0.49 & 0.59 & 0.57 & 0.56 \\ 10 & 0.48 & 0.57 & 0.56 & 0.55\end{array}$




\section{References}

[1] S. E. A. of Ireland (SEAI), Energy in ireland 2019 report, Tech. rep., SEAI (Sep. 2019).

[2] EirGrid, All-island generation capacity statement 2017-2026', EirGrid.

[3] E. Department of Communications, N. Resources, Offshore renewable energy development plan: A framework for the sustainable development of ireland's offshore renewable energy resource, Tech. rep., Government of Ireland (2014).

[4] R. Atan, J. Goggins, S. Nash, A detailed assessment of the wave energy resource at the atlantic marine energy test site, Energies 9 (11) (2016) 967.

[5] I. López, J. Andreu, S. Ceballos, I. M. de Alegría, I. Kortabarria, Review of wave energy technologies and the necessary power-equipment, Renewable and sustainable energy reviews 27 (2013) 413-434.

[6] A. Foley, B. Ó. Gallachóir, E. McKeogh, D. Milborrow, P. Leahy, Addressing the technical and market challenges to high wind power integration in ireland, Renewable and Sustainable Energy Reviews 19 (2013) 692-703.

[7] C. Pérez-Collazo, D. Greaves, G. Iglesias, A review of combined wave and offshore wind energy, Renewable and Sustainable Energy Reviews 42 (2015) 141-153.

[8] A. Azzellino, C. Lanfredi, L. Riefolo, P. Contestabile, D. Vicinanza, Combined exploitation of offshore wind and wave energy in the italian seas: a spatial planning approach, Frontiers in Energy Research 7 (2019) 42.

[9] S. Gallagher, R. Tiron, E. Whelan, E. Gleeson, F. Dias, R. McGrath, The nearshore wind and wave energy potential of ireland: a high resolution assessment of availability and accessibility, Renewable Energy 88 (2016) $494-516$.

[10] F. Fusco, G. Nolan, J. V. Ringwood, Variability reduction through optimal combination of wind/wave resources-an irish case study, Energy 35 (1) (2010) 314-325.

[11] W. M. Organization, Wmo guidelines on the calculation of climate normals (2017).

[12] A. Kareem, A. Tamura, Advanced structural wind engineering, Springer, 2015

[13] M. Abbaspour, R. Rahimi, Iran atlas of offshore renewable energies, Renewable Energy 36 (1) (2011) 388-398.

[14] B. Cahill, T. Lewis, Wave energy resource characterisation of the atlantic marine energy test site, International Journal of Marine Energy 1 (2013) 3-15.

[15] B. Cahill, Characteristics of the wave energy resource at the atlantic marine energy test site, Ph.D. thesis, University College Cork, Ireland (2013).

[16] B. Cahill, T. Lewis, Wave periods and the calculation of wave power, in: Proceedings of the 2nd Marine Energy Technology Symposium (METS2014), 2014. URL http://hdl.handle.net/10919/49206

[17] A. M. E. Research, Atlas of UK Marine Renewable Energy Resources, Dti, 2004

[18] M. E. McCormick, Ocean wave energy conversion, Courier Corporation, 2013.

[19] M. K. Ochi, Ocean waves: the stochastic approach, Vol. 6, Cambridge University Press, 2005.

[20] L. Rusu, D. Ganea, E. Mereuta, A joint evaluation of wave and wind energy resources in the black sea based on 20-year hindcast information, Energy Exploration \& Exploitation 36 (2) (2018) 335-351.

[21] C. Kalogeri, G. Galanis, C. Spyrou, D. Diamantis, F. Baladima, M. Koukoula, G. Kallos, Assessing the european offshore wind and wave energy resource for combined exploitation, Renewable energy 101 (2017) 244-264.

[22] S. Astariz, G. Iglesias, Output power smoothing and reduced downtime period by combined wind and wave energy farms, Energy 97 (2016) 69-81.

[23] J. F. Chozas, J. P. Kofoed, H. C. Sørensen, Predictability and variability of wave and wind: wave and wind forecasting and diversified energy systems in the danish north sea, Aalborg University, Dept. of Civil Engineering, Aalborg (Denmark).

[24] L. Cradden, H. Mouslim, O. Duperray, D. Ingram, Joint exploitation of wave and offshore wind power, in: Proceedings of the Ninth European Wave and Tidal Energy Conference (EWTEC), Southampton, UK, 2011 , pp. 5-9.

[25] J. F. Chozas, H. Sørensen, N. H. Jensen, Economic benefit of combining wave and wind power productions in day-ahead electricity markets, in: 4th International Conference on Ocean Energy, 2012, pp. 1-10.

[26] E. D. Stoutenburg, N. Jenkins, M. Z. Jacobson, Power output variations of co-located offshore wind turbines and wave energy converters in california, Renewable energy 35 (12) (2010) 2781-2791.

[27] S. Astariz, G. Iglesias, Enhancing wave energy competitiveness through co-located wind and wave energy farms. a review on the shadow effect, Energies 8 (7) (2015) 7344-7366.

[28] S. Astariz, C. Perez-Collazo, J. Abanades, G. Iglesias, Co-located wave-wind farms: Economic assessment as a function of layout, Renewable Energy 83 (2015) 837-849.

[29] S. Astariz, A. Vazquez, M. Sánchez, R. Carballo, G. Iglesias, Co-located wave-wind farms for improved o\&m efficiency, Ocean \& coastal management 163 (2018) 66-71.

[30] S. Gallagher, R. Tiron, F. Dias, A long-term nearshore wave hindcast for ireland: Atlantic and irish sea coasts (1979-2012), Ocean Dynamics 64 (8) (2014) 1163-1180. 